ANL- 6458

Reactor Technology (TID-4500, 17th Ed.) AEC Research and Development Report

ARGONNE NATIONAL LABORATORY

9700 South Cass Avenue

Argonne, Illinois

\title{
KINETICS OF TREAT USED AS A TEST REACTOR
}

by

C. E. Dickerman and R.D. Johnson

Reactor Engineering Division

and

J. Gasidlo

Idaho Division

May 1962

Operated by The University of Chicago under

Contract W-31-109-eng-38 


\section{DISCLAIMER}

This report was prepared as an account of work sponsored by an agency of the United States Government. Neither the United States Government nor any agency Thereof, nor any of their employees, makes any warranty, express or implied, or assumes any legal liability or responsibility for the accuracy, completeness, or usefulness of any information, apparatus, product, or process disclosed, or represents that its use would not infringe privately owned rights. Reference herein to any specific commercial product, process, or service by trade name, trademark, manufacturer, or otherwise does not necessarily constitute or imply its endorsement, recommendation, or favoring by the United States Government or any agency thereof. The views and opinions of authors expressed herein do not necessarily state or reflect those of the United States Government or any agency thereof. 


\section{DISCLAIMER}

Portions of this document may be illegible in electronic image products. Images are produced from the best available original document. 


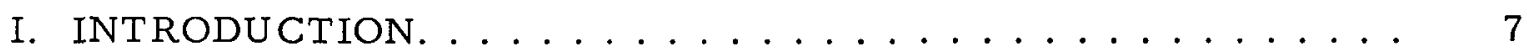

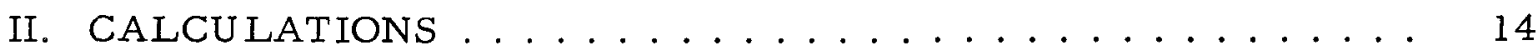

A. Data Reduction .................... 14

1. Data. . . . . . . . . . . . . . . . . 14

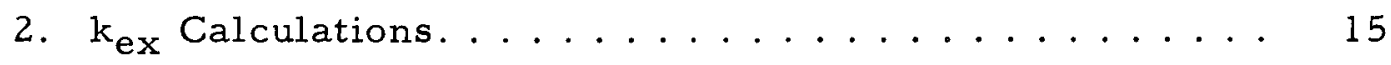

B. Theoretical Calculations................ 22

1. Feedback ................... 22

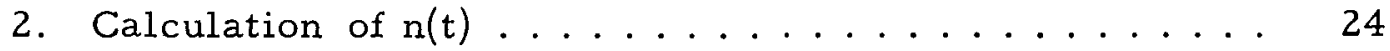

3. Reactor Power Calculations . . . . . . . . . . 25

4. Normalization . . . . . . . . . . . . . 26

III. COMPARISON OF EXPERIMENT AND CALCULATIONS FOR TREAT TEMPERATURE-LIMITED TRANSIENTS . . . . . . 27

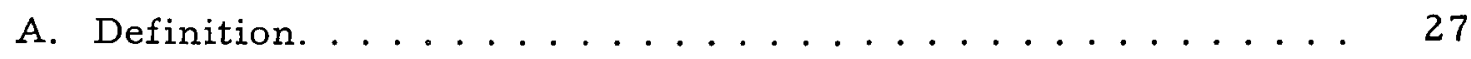

B. Direct Comparisons. . . . . . . . . . . . . . . 27

1. Calculated and Experimental Feedback. . . . . . . 27

2. Maximum Transient Power . . . . . . . . . . 28

3. Integrated Reactor Power . . . . . . . . . . . . 29

4. Maximum Core Temperature ............. 30

C. Transient Power Curve Shapes ............... 31

D. Conclusions ........................... 35

IV. SPECIALLY PROGRAMMED TRANSIENTS . . . . . . . 37

A. Clipped Transients ................... 37

B. Constant-power Transients . . . . . . . . . . . 42

1. General Characteristics .............. 42

2. Limitations on Constant-power Transients . . . . . 47

V. PERFORMANCE EXTRAPOLATIONS. ............ 55

ACKNOW LEDGMENT. . . . . . . . . . . . . . . . 58

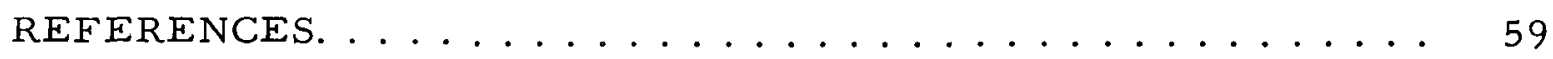


$\bullet$

$\bullet$ 


\section{LIST OF FIGURES}

No.

Title

Page

1. TREAT Reactor, Vertical Section .............. 8

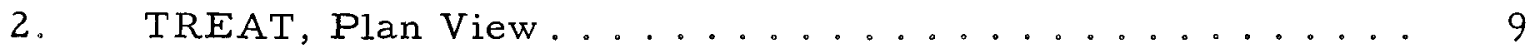

3. Typical Slotted-core Loading Diagram (First Meltdown

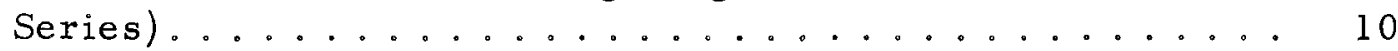

4. Radial Distribution of Core Temperature Comparison between Solid-core and Slotted-core Loadings........ 11

5. Experimental Power Curves for Seven TREAT Transients. . 13

6. $k_{\text {ex }}$ vs Asymptotic Period for the TREAT Reactor ...... 16

7. Comparison of Initial $k_{\text {ex }}$ from Asymptotic Period with That from Rod Calibrations, Slotted Core Loading. ........ 16

8. Power Traces from Transient $24-k_{\mathrm{ex}}(0)=0.68 \% \ldots 18$

9. Power Traces from Transient $174-\mathrm{k}_{\mathrm{ex}}(0)=2.42 \% \ldots 19$

10. $k_{\text {ex }}(t)$ Calculated for Transient $24 \ldots \ldots 20$

11. $k_{e x}(t)$ Calculated for Transient $174 \ldots \ldots 21$

12. Temperature Coefficient of Reactivity Calculated for

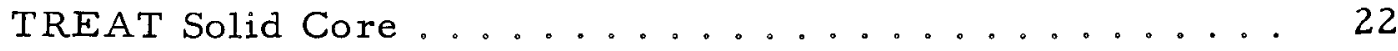

13. $k_{\text {ex }}$ vs Integrated Neutron Density Relationships ....... 23

14. Typical Core-temperature Traces.............. 24

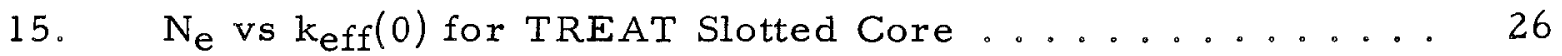

16. Comparison of Experimental Feedback Data and Feedback Curves.

17. Comparison of Experimental and Calculated Maximum

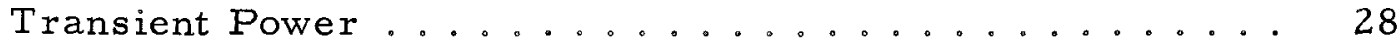

18. Experimental Values of Integrated Reactor Power ...... 29

19. Comparison of Calculated and Experimental Integrated Reactor Power, Corrected to Uniform Final Time ...... 30

20. Comparison of Calculated and Experimental Maximum Reactor Temperatures, Corrected to Uniform Final Time....

21. Comparison of Calculated and Experimental Power Curve Shapes for Transient Initiated with $0.62 \% \mathrm{k}_{\mathrm{ex}} \ldots \ldots$ 
LIST OF FIGURES

No.

Title

Page

22. Comparison of Calculated and Experimental Power Curve Shapes for Transient Initiated with $1.20 \% \mathrm{k}_{\mathrm{ex}} \ldots \ldots . .$.

23. Comparison of Calculated and Experimental Power Curve Shapes for Transient Initiated with $1.61 \% \mathrm{k}_{\mathrm{ex}} \ldots \ldots . . .$.

24. Comparison of Calculated and Experimental Power Curve Shapes for Transient Initiated with $2.42 \% \mathrm{k}_{\mathrm{ex}} \ldots \ldots . .$.

25. Power Peak Half-Width Comparison ............

26. Comparison of Power One Half-Width After Maximum

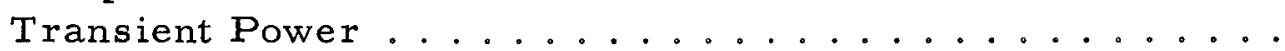

27. Comparison of Calculated and Experimental Power Curve Shapes for $1.5 \% \mathrm{k}_{\mathrm{ex}}$ Transient Clipped Before TemperatureLimited Power Peak ...................

28. Calculated Reactor Power vs Time for Six Clipped $1.5 \% \mathrm{k}_{\mathrm{ex}}$

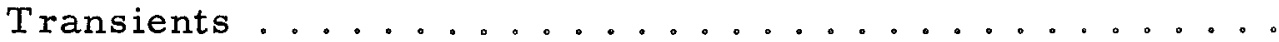

29. Half-Width of Reactor Power Peaks for Transients Clipped Before and At Temperature-Limited Power Peak.......

30. Ratio of Integrated Reactor Power at Clip Setting to Total Integrated Reactor Power for Transients Clipped Before and At Temperature-Limited Power Peak..........

31. Total Integrated Transient Power as a Function of Integrated Power at Clip Setting and Delay Time for $1.5 \% \mathrm{k}_{\mathrm{ex}}(0)$

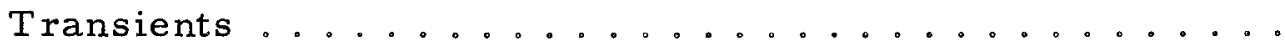

32. Total Integrated Transient Power as a Function of Integrated Power at Clip Setting and Delay Time for $\mathrm{k}_{\mathrm{ex}}(0)=$ $1.1 \%, 1.5 \%$, and $1.8 \% \ldots \ldots \ldots$

33. Integrated Reactor Power at Temperature-Limited

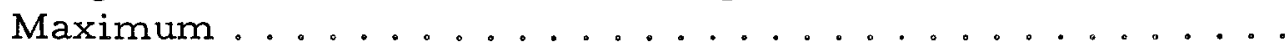

34. Calculated Curves of $\mathrm{k}_{\mathrm{ex}}$ vs Time for $0.50 \% \mathrm{k}_{\mathrm{ex}}(0)$

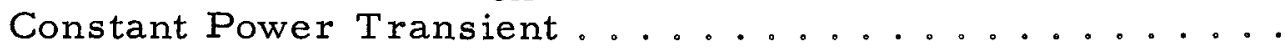

35. Calculated Sustaining $\mathrm{k}_{\mathrm{ex}} \mathrm{vs}$ Time for $0.50 \% \mathrm{k}_{\mathrm{ex}}(0)$ Constant Power Transient ................

36. Calculated Sustaining $k_{\text {ex }}$ vs Time Curves ......... 46

37. Variation in Allowable Duration of Constant Power with

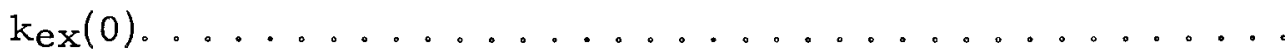




\section{LIST OF FIGURES}

No. $\underline{\text { Title }}$

38. Variation in Allowable Integrated Power with $\mathrm{k}_{\mathrm{ex}}(0)$ for

Constant Power Transients ............... 49

39. Reactor Power vs Time for Transient $126-\mathrm{k}_{\mathrm{ex}}(0)=0.69 \%$. 50

40. Reactor Power vs Time for Transient $127-k_{\text {ex }}(0)=0.74 \%$. 51

41. Reactor Power vs Time for Transient $161-\mathrm{k}_{\mathrm{ex}}(0)=0.81 \%$. 51

42. Reactor Power vs Time for Transient $231-\mathrm{k}_{\mathrm{ex}}(0)=0.67 \%$. 51

43. Reactor Power vs Time for Transient $236-\mathrm{k}_{\mathrm{ex}}(0)=0.49 \%$. 52

44. Extrapolation of Maximum Transient Power for Temperature-Limited Transients, Slotted Core Loading . . . 56

45. Extrapolation of Integrated Transient Power for Temperature-Limited Transients, Slotted Core Loading . . . 56

46. Extrapolation of Maximum Core Temperature for Temperature-Limited Transients, Slotted Core Loading ... 
$\bullet$

$\bullet$ 


\title{
KINETICS OF TREAT USED AS A TEST REACTOR
}

\author{
by \\ C. E. Dickerman, R. D. Johnson, and J. Gasidlo
}

\section{INTRODUCTION}

An experimental program designed to study the meltdown behavior of fast reactor fuel elements under in-pile transient conditions has been undertaken by Argonne National Laboratory with the use of the Transient Reactor Test Facility (TREAT). The reactor went critical in February, 1959. Several months of engineering checkout and steady-state experimentation were followed in the summer of 1959 by a series of temperaturelimited reactor-physics, transient kinetics experiments. In September, 1959, the first meltdown experiments were performed. During the next 18 months, approximately 100 meltdown tests were run on dry samples in TREAT. A status report on the results of these experiments on sample fast reactor fuel elements has been prepared. (1)

This report presents an analysis of the reactor kinetics of TREAT used as a pulsed, engineering test reactor for the fast reactor fuel element studies. Those studies are continuing. This kinetics analysis is being given to provide a description of the reactor performance over a wide range of conditions of interest in its use as a test reactor, and as a supplement to the status report of meltdown experimentation.(1)

TREAT design was described at the Second Geneva Conference on the Peaceful Uses of Atomic Energy. (2) Reactor-physics calculations based on the design have been published. $(3,4)$ Engineering details have been reported in the reactor hazards summary report $(5)$ and the engineering-design report. (6)

Briefly, TREAT was designed for use as a neutron source for transient experiments requiring a large integrated thermal neutron flux in a single burst, with the flux distributed over a large sample volume. It is a graphite-moderated reactor with fuel consisting of 16 - to $18-\mu$ uranium oxide particles in a graphite matrix. Thus, the moderator provides a large heat sink in close contact with the fuel.

Use of the graphite moderator as a heat sink introduces a sizeable, prompt, negative temperature coefficient of reactivity, since a rise in graphite temperature produces a rise in the "temperature" of the thermal neutrons and thus increases the probability of thermal neutron leakage from the core. 
A side view of TREAT through the central, vertical plane is shown in Fig. 1, and a plan view of the reactor (taken at a horizontal cut through the center of the core) shown in Fig. 2. In its simplest configuration, the reactor has a right cylindrical core, completely reflected by graphite. Each core element consists of a Zircaloy-clad urania-graphite core section, $122 \mathrm{~cm}$ high, with aluminum-clad graphite top and bottom reflector sections attached. The element cross section is a square, $10 \mathrm{~cm}$ on a side, with truncated corners which form channels permitting the flow of air coolant for low-power steady-state operation or for cooling the reactor after a transient. Dummy fuel elements, in which graphite has been substituted for the urania-graphite fuel mixture, are available for construction of an inner reflector within the reactor core cavity. Special access-hole fuel elements and dummy fuel elements were built in which the central $61 \mathrm{~cm}$ of fuel had been removed and a Zircaloy-clad hole, approximately $57.6 \mathrm{~cm}$ high by $8.9 \mathrm{~cm}$ wide, was made. Through the use of these accesshole elements and by retracting the proper reflector-access block, it is possible to open up a large viewing slot running from the outside of the reactor to the center of the core.

(HLL DIMEasions IN cm)

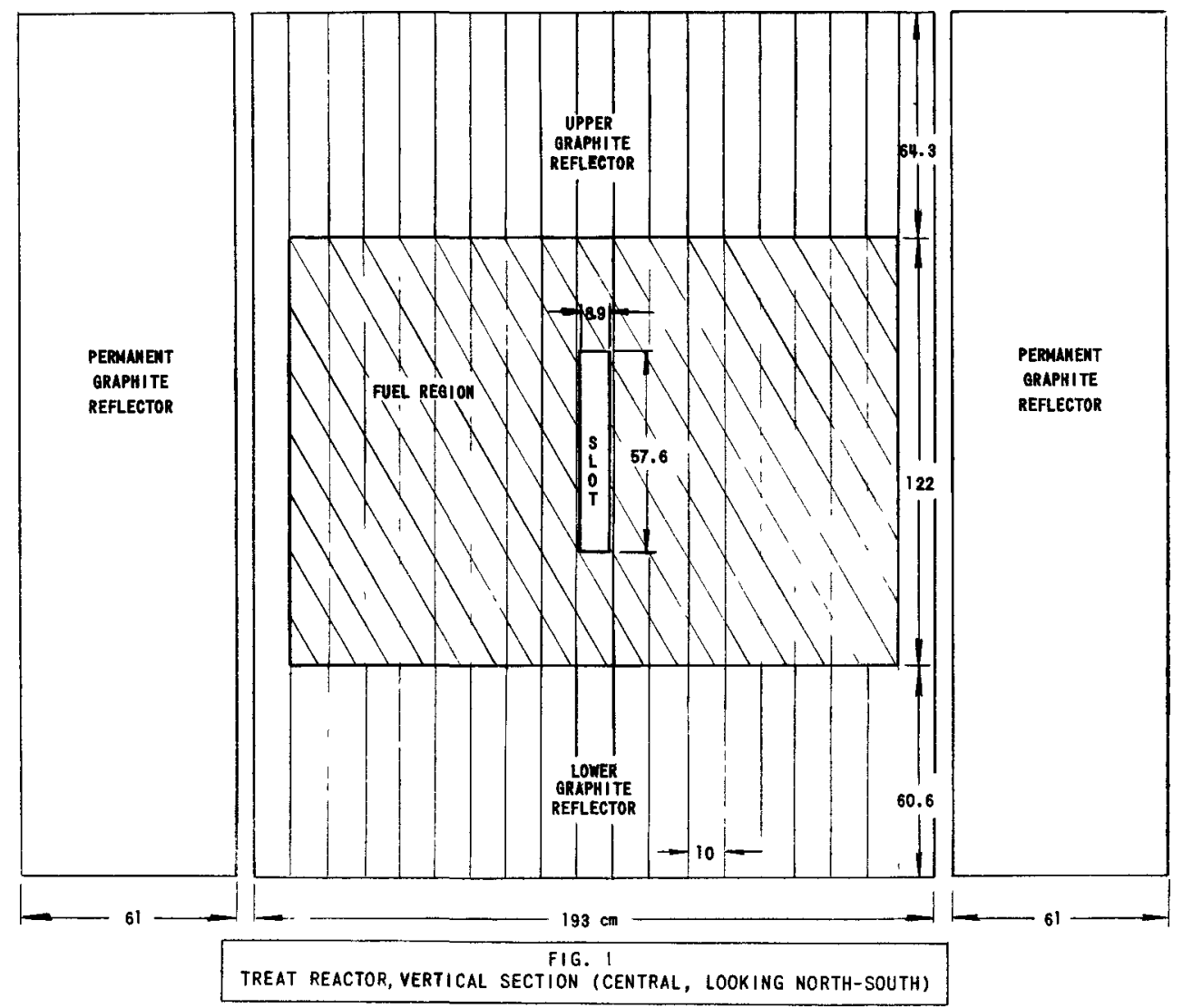




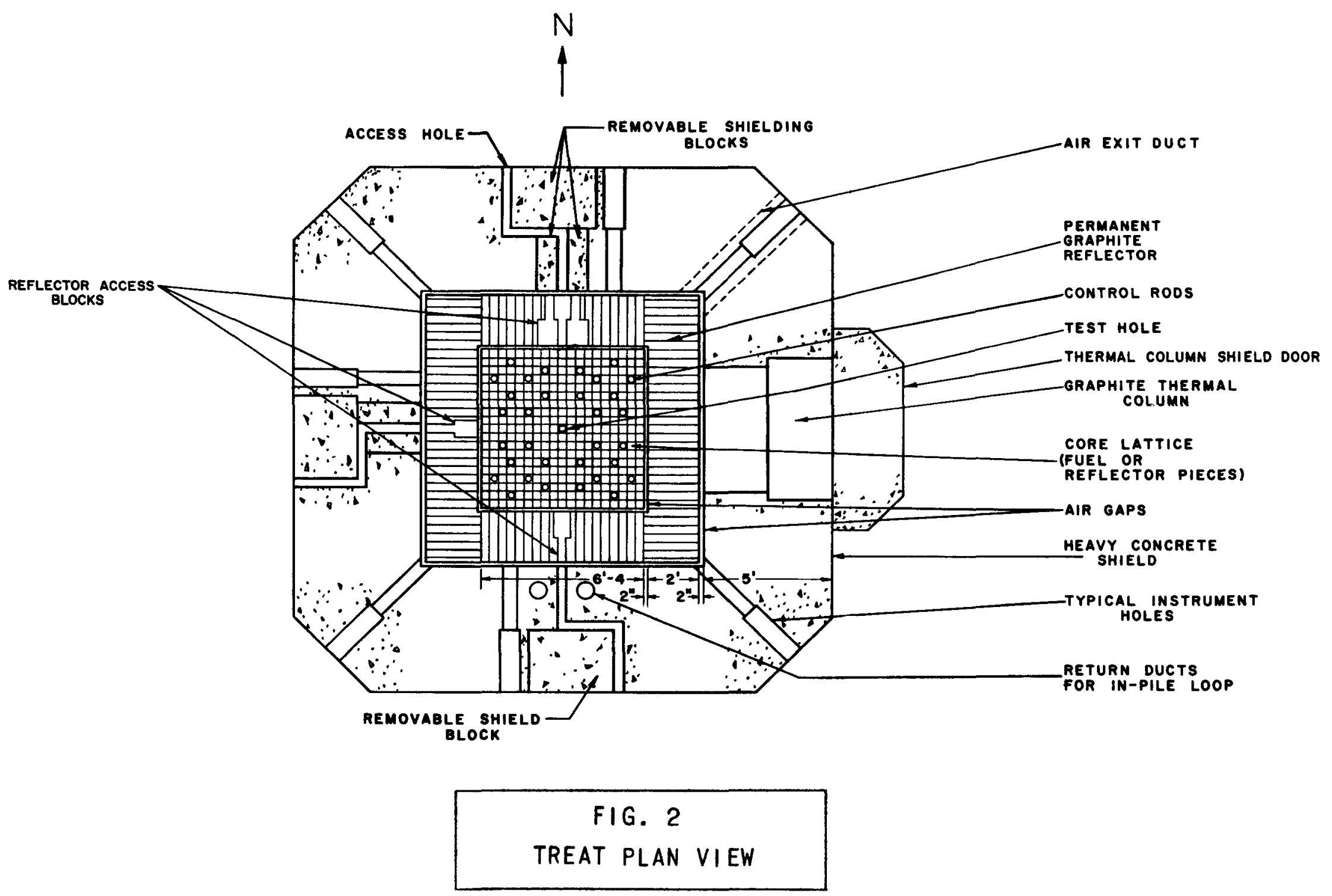


When TREAT is used in its normal role as a transient engineering test reactor, the central fuel element is replaced by a special experimental dummy element containing a

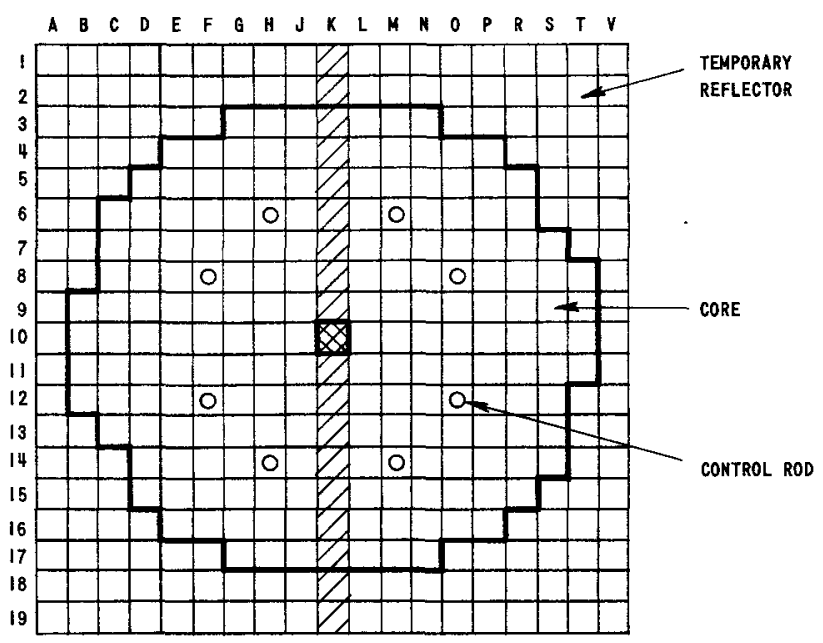

180 REgULAR FUEL ELEMENTS

I3 SLOTTED FUEL ELEMENTS

8 CONTROL RODS

TEST HOLE

Q SLOTTED ELgUENTS

FIG. 3
TYPICAL SLOTTED-CORE LOADING DIAGRAM
(FIRST MELTDOWN SERIES)

sample, and there may be one or two viewing slots. In order to permit an extensive program of checkout and evaluation of advanced instrumentation for the meltdown project, the reactor was loaded consistently for meltdown experimentation( 1 ) with 2 viewing slots forming one continuous gap, except for the dummy experimental element in the test hole (see Fig. 2), through the core from the north face to the south face. The number of fuel elements was adjusted to provide an adequate $\mathrm{k}_{\mathrm{ex}}$ for transients, usually $\sim 2 \%$ with experimental dummy element, meltdown sample, and the N-S slot. Figure 3 shows a typical reactor-loading diagram for this slotted configuration: the loading for the first series of meltdown experiments.

An analysis of the reactor kinetics of TREAT, loaded in its simplest configuration of a solid, cylindrical core without experimental dummy element or slots, has been published.(7) That analysis was based on a study of a series of temperature-limited reactor transient experiments performed as a part of the experimental reactor-physics program(8) carried out prior to initiation of engineering tests in TREAT. TREAT, as loaded for a typical meltdown experiment, has been changed considerably from the corresponding solid-core loading having the same excess reactivity.

(1) The $k_{\text {ex }}$ worth of the straight-through $\mathrm{N}-\mathrm{S}$ double slot was measured to be $\Delta \mathrm{k}=-5.75 \% .(8)$

(2) The $\mathrm{k}_{\mathrm{ex}}$ worth of a dummy element replacing a regula $\mathrm{r}$ fuel element at the central core position has been measured as $\Delta \mathrm{k}=-0.55 \%$.

(3) The $k_{e x}$ contribution of a meltdown sample plus its standard dry, opaque containment capsule has been estimated to range between -0.33 and $-0.37 \% \triangle \mathrm{k}_{\text {ex }}$ for samples of the type studied during the initial experimentation. One measurement of the 
worth of capsule + sample was made, yielding a result of $\Delta \mathrm{k}_{\mathrm{ex}}=-0.4 \%$ for a combination predicted to have a worth of $\Delta \mathrm{k}_{\mathrm{ex}}=-0.37 \%$.

(4) Distribution of the flux in the core is changed by the absence of fuel in the slot and neutron streaming down the slot, so that there is a flux depression in and near the slot and the maximum core flux occurs at points $\sim 20 \mathrm{~cm}$ to the east and west of the core center, rather than at a single point near the geometrical center. $(7,8)$

Figure 4 demonstrates graphically the perturbations caused by sample, sample holder, and slot. It shows measured core temperatures

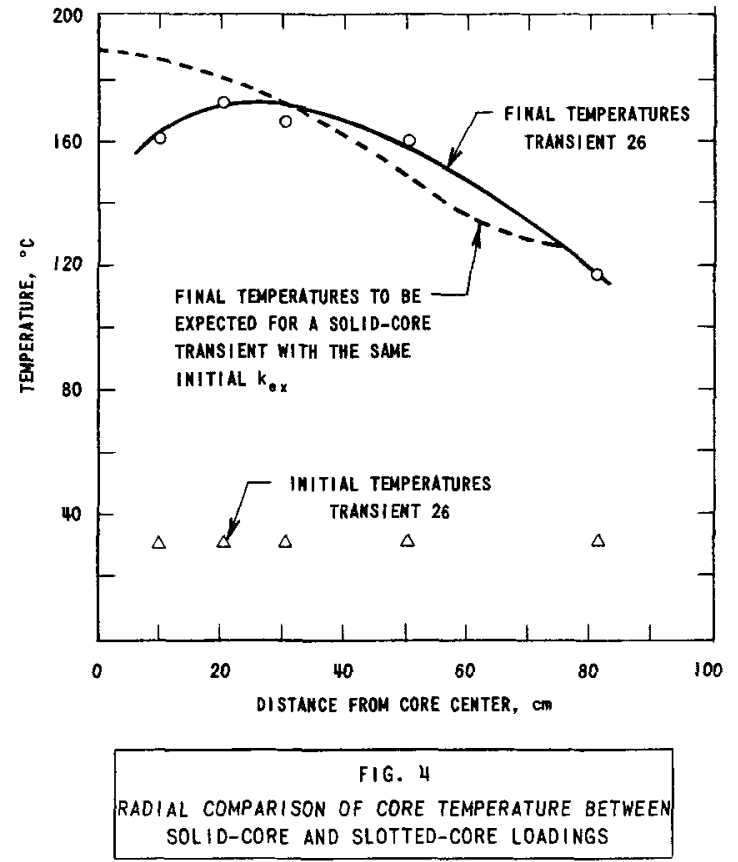
scribe the effects of flux depression and neutron streaming on lifetime, neutron thermalization, and leakage.

This analysis was prepared with two aims: to deduce a reasonable and consistent description of the TREAT kinetics for operation with the large perturbations introduced by experimental requirements of the meltdown project, and to check the degree of agreement between such experimental operation and predictions based on the earlier solid-core analysis. (7) Accordingly, the work given herein follows an outline similar to that of the solid-core analysis, and consisted of the following steps:

First, experimental reactor feedback data were extracted from records of temperature-limited TREAT transients. Values of neutron density as a function of time were taken from the oscillograph traces of 
reactor power instrument output. The information about neutron density, a measured value of prompt neutron lifetime, and calculated fractions of effective delayed neutrons were used as input data for calculations of $\mathrm{k}_{\mathrm{ex}}$ as a function of time, made with an electronic computer. From these computer results, values of $k_{e x}$ as a function of integrated neutron density or temperature during the transient were obtained. This phase of the investigation, as in the case of the solid-core analysis, (7) was used only for purposes of orientation, because of scatter in the feedback-data points. Only 5 slotted-core transient experiments were thus studied: they provided experimental feedback data over the range of reactor operation during the period of meltdown experimentation covered by this report.

Second, experimental power traces were compared with results of calculations of reactor power based on the theoretical calculations of $\mathrm{k}_{\mathrm{eff}}$ as a function of core temperature for a TREAT-like system, normalized to experiment for the simple solid-core configuration. (7) Reasonable agreement was found between predictions of reactor power based on the solidcore feedback and the results of the meltdown experiments. This feedback was normalized to provide better general agreement with respect to peak power for the meltdown transients. In general, it was found that calculations based on the solid-core feedback and the peak power-normalized slottedcore feedback bracketed experimental results.

Third, the resulting normalized slotted-core feedback was used in attempts to reproduce features of the experimental power data. In the case of temperature-limited transients, checks were made for power curve shapes, integrated transient power, and maximum reactor temperatures. For meltdown experiments in which the power pulses were clipped by programmed rod scram at relatively low integrated power, general agreement was sought for power curve shapes, peak power as a function of power at scram, and integrated power as a function of integrated power at scram. Some investigation was also made of the features of "flattened" reactor transients, in which the power burst is initiated with a given $k_{e x}$, the power level is limited by the feedback, and the power is then sustained at a moreor-less constant value by insertion of additional $k_{e x}$ to counter the loss of reactivity due to reactor heating.

Finally, theoretical calculations were extended to higher reactor temperatures than those encountered in the test transients, and estimates were made of temperature-limited kinetics performance to be expected during more severe reactor transients with a similar loading.

The range of transient power, power curve shapes, and transient durations covered in this analysis is illustrated in Fig. 5, which shows reactor power curves for 7 typical slotted-core, temperature-limited transients performed during the course of the meltdown experiments. (1) 


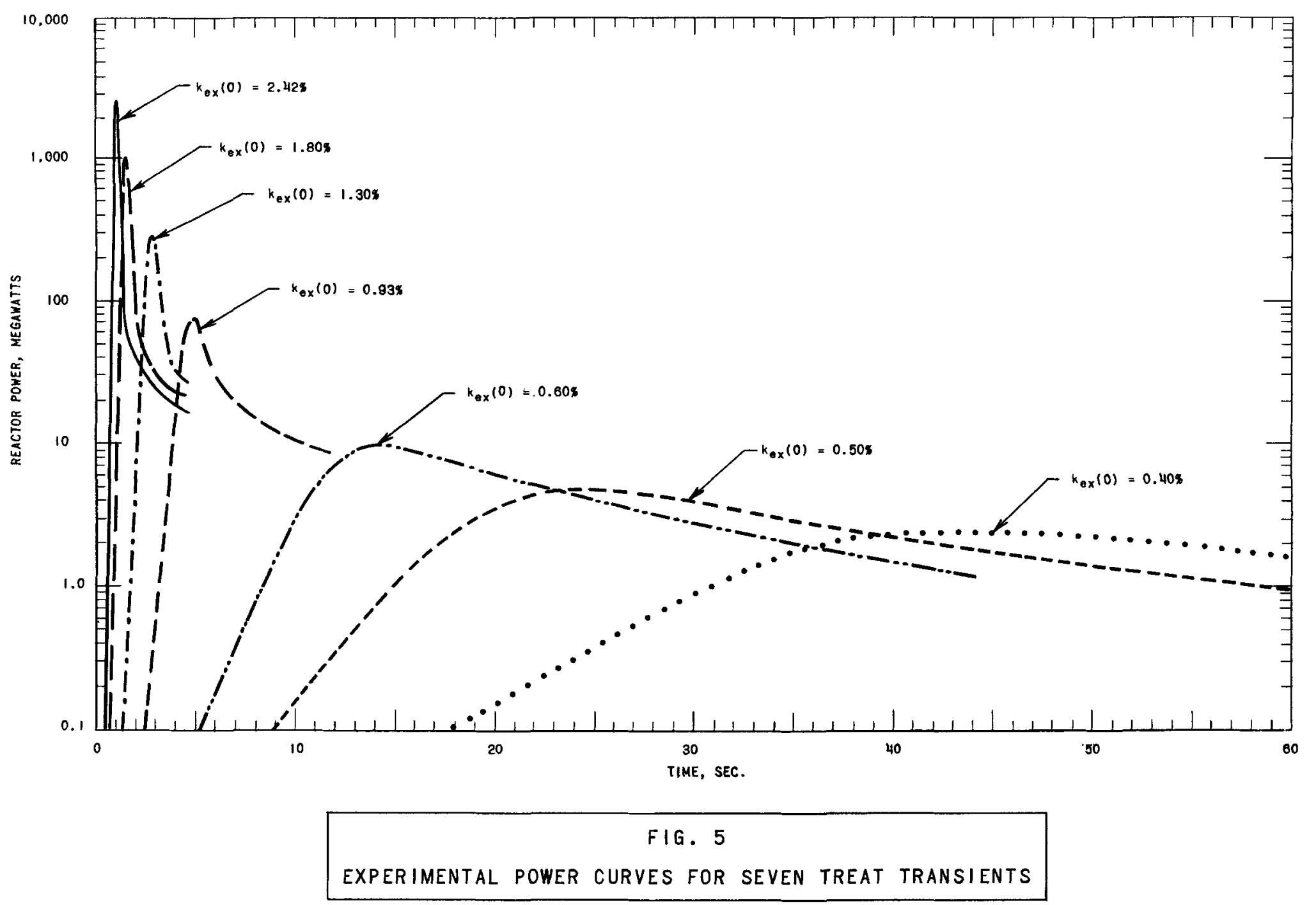




\section{CALCULATIONS}

A. Data Reduction

1. Data

Transient information used in this analysis of TREAT kinetics performance during meltdown experiments consisted of the following data:

(1) Oscillograph traces of transient output from 2 boron chambers located in the reactor shielding, and driving 2 linear amplifiers. The chambers were designated as Safety 1 and Safety 2.

(2) Oscillograph traces of transient output from another pair of boron chambers in the shielding. These chambers drive logarithmic amplifiers and were named Log 1 and Log 2.

(3) Before-and-after readings of the Brown-recorder record of output from a thermocouple located, within experimental error, at the point of maximum reactor temperature.

(4) Total number of counts recorded from either one or two $\mathrm{U}^{235}$ fission chambers located in the reactor shielding.

(5) Control-rod positions at the pretransient criticality check and immediately preceding the firing of the transient rod drive.

Chamber calibration techniques are discussed elsewhere, (8) as are the uncertainties and ranges of application of data from the sources listed above. (7) As before, the log power instruments were used only to determine relative reactor power; they provided values of initial transient periods, general characteristics of transient power curves, and power levels near the end of transients. Records of the linear instrument output were used to obtain values of maximum transient power and quantitative data for power within approximately one decade of the maximum.

In order to perform calculations resulting in estimates of meltdown-sample temperature-rise rates, temperature gradients within meltdown samples, and maximum sample temperatures, it was found necessary to establish descriptions of pulse shapes of reactor power and maximum power as a function of initial $k_{\mathrm{ex}}$. The temperature details depend sensitively upon pulse peak power, width of power excursion, and magnitude of power "tail." (1) Hence, power records for a given transient were compared with each other for consistency, then checked with values of maximum 
peak power, pulse width, and indices of power decrease after the peak that gave good general agreement for the complete set of transient power records.

Two of the 3 techniques used previously $(7,8)$ for measuring integrated reactor power were utilized: measurement of rises of core temperature and recording on scalers the outputs of either one or two fission counters. Values of integrated reactor power for the meltdown transients were obtained by combining data from these techniques.

TREAT control rods were calibrated by the "rod bump" method with the reactor loaded in a typical meltdown configuration and a Chemical Engineering experimental autoclave $(9)$ in the central core position. The resulting calibration curve, (8) which has been in general use for TREAT experimental work, makes it possible to obtain values of initial transient $k_{e x}$ independent of the initial kex calculated from the initial periods of the log power records. Effects of coupling between different control rods were minimized by the standard operating procedure for temperature-limited or clipped transients (but not including flattened bursts, which require a more complicated pretransient rod configuration) which includes the following steps:

(1) Pretransient criticality check with Rod 1, only, in the reactor core.

(2) Movement of Rod 1 such that its change in worth is equal to the desired initial $\mathrm{k}_{\mathrm{ex}}$, compensated, as necessary, by insertion of Rod 2 into the core to maintain criticality.

(3) Initiation of the transient by firing Rod 2 from the core.

\section{2. $\mathrm{k}_{\mathrm{ex}}$ Calculations}

Values of initial $k_{e x}$, or $k_{e x}(0)$, were obtained by comparing the averaged asymptotic reactor periods read from the log power instrument data with calculations of asymptotic reactor period made with the measured TREAT prompt neutron lifetime $\left(9.0 \times 10^{-4} \mathrm{sec}\right),(8)$ the effective delayed neutron fractions calculated for the solid-core reactor, (7) and the Argonne IBM 704 code RE 130.(10) This code solves the inhour equation

$$
\frac{k_{e x}}{1+k_{e x}}=\frac{l}{\ell+T}+\frac{T}{\ell+T} \sum_{i} \frac{\beta_{i \text { eff }}}{1+\lambda_{i} \beta_{i} \text { eff }}
$$

where $\ell$ is the prompt neutron lifetime, $T$ is the asymptotic reactor period, $\beta_{i}$ eff is the effective fraction for the $i^{\text {th }}$ delayed neutron group, and $\lambda_{i}$ is the decay constant of the ith precursor group. Results of these calculations for TREAT are shown in Fig. 6. 


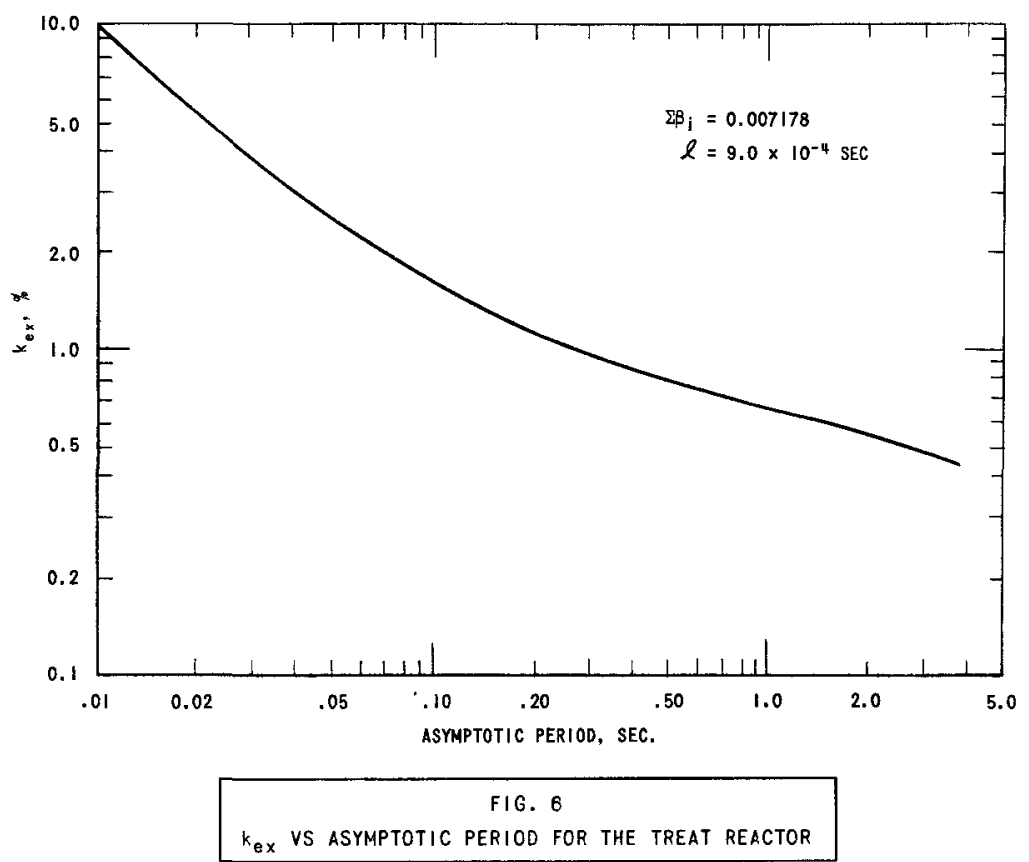

A comparison between values of initial kex obtained from the control-rod calibration curve and those obtained from measurements of the asymptotic reactor periods is given in Fig. 7, in which the ratio of $k_{e x}(0)$ from asymptotic periods to $k_{e x}(0)$ from rod calibrations is graphed as a function of the latter. In the absence of detailed measurements of prompt neutron lifetime for the specific core configurations considered here, Fig. 7 cannot be used to draw a definitive conclusion as to the suitability of the particular values of $\beta_{i}$ eff used. However, the figure does not show any clear deviation of the type to be expected from use either of the wrong value of $l$ or of the wrong values of $\beta_{i}$ eff. Rod calibrations were made with large values of $T$, for which the inhour equation has the asymptotic form

$$
k_{\text {ex }} \sim \frac{1}{T} \sum_{i} \frac{\beta_{\text {i eff }}}{\lambda_{i}}
$$

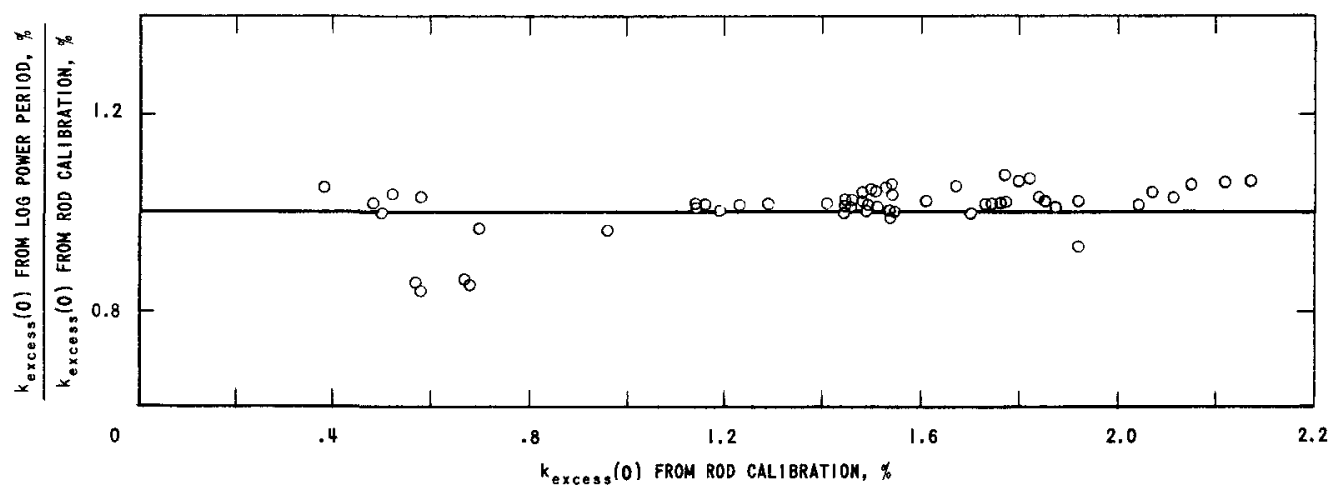

FIG. 7

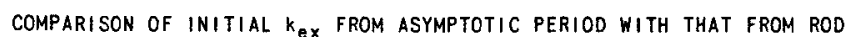
CALIBRATIONS, SLOTTED CORE LOADING 
For super-prompt-critical periods, the equation has the asymptotic form

$$
k_{\text {ex }} \sim \frac{\ell}{\mathrm{T}}+\beta_{\mathrm{eff}}
$$

Hence, for the case of either wrong $l$ or wrong $\beta_{i}$ eff, the ratio would be essentially unity for $\mathrm{k}_{\mathrm{ex}}(0) \approx \beta_{\mathrm{eff}}$, but would deviate therefrom for higher values of $k_{\mathrm{ex}}(0)$, the deviation becoming greater the larger the $\mathrm{k}_{\mathrm{ex}}(0)$. No deviation of this kind is apparent within experimental uncertainties. The average of the points shown in Fig. 7 is 1.017 - reasonable agreement within the estimated uncertainties in rod calibration, recorder trace reading, methods of calculating $\beta_{i \text { eff }}(7)$ and the lifetime measurements. (8)

Calculations of $k_{e x}$ as a function of time were made as before ${ }^{(7)}$ using the Argonne IBM 704 code Re 171, (11)* which solves the one-energy group, space-independent coupled reactor kinetics equations

$$
\frac{\dot{n}}{n}=\left[k_{e x}\left(1-\beta_{e f f}\right)-\beta_{e f f}\right] \frac{1}{\ell}+\frac{1}{n} \sum_{i} \lambda_{i} C_{i}
$$

and

$$
\dot{C}_{i}=\left(1+k_{e x}\right) n \frac{\beta_{i \text { eff }}}{l}-\lambda_{i} C_{i},
$$

where $\mathrm{n}$ is the neutron density, $\beta$ eff is the effective delayed neutron fraction, and $C_{i}$ is the concentration of the $i^{\text {th }}$ precursor group.

Three calculations were made of $k_{e x}$ as a function of time for 5 test transients: the first 4 meltdown experiments ( $T$ ransients $24,26,27$, and 28) which provided early orientation and assistance on experimental planning, and Transient 174 (which extended the range of the experimental feedback data to include higher initial $k_{e x}$ ). Values of relative reactor power as a function of time from Safety 1, Safety 2, and Log 1 were used in order to cover the full range of the transients. Absolute normalization of the instruments was not necessary at this stage, since the kinetics equations depend on relative, not absolute, power (see Eqs. 4. and 5).

Outputs of the 4 power instruments for Transients 24 and 174 are shown in Figs. 8 and 9, respectively. Readings from the linear instruments have been converted to megawatts (left-hand scales). The Log 1 and Log 2 records have not been converted to megawatts, but remain in amperes (right-hand scales) in the figures. Results of the $k_{\text {ex }}$ calculations for these transients are given in Fig. 10 (Transient 24) and Fig. 11 (Transient 174). The data in Figs. 8 to 11 are typical of those for all 5 transients selected for direct analysis of the reactor feedback relationship.

*This code is the IBM-704 version of space-independent kinetics code RE-31(12) which was written for the AVIDAC computer. 


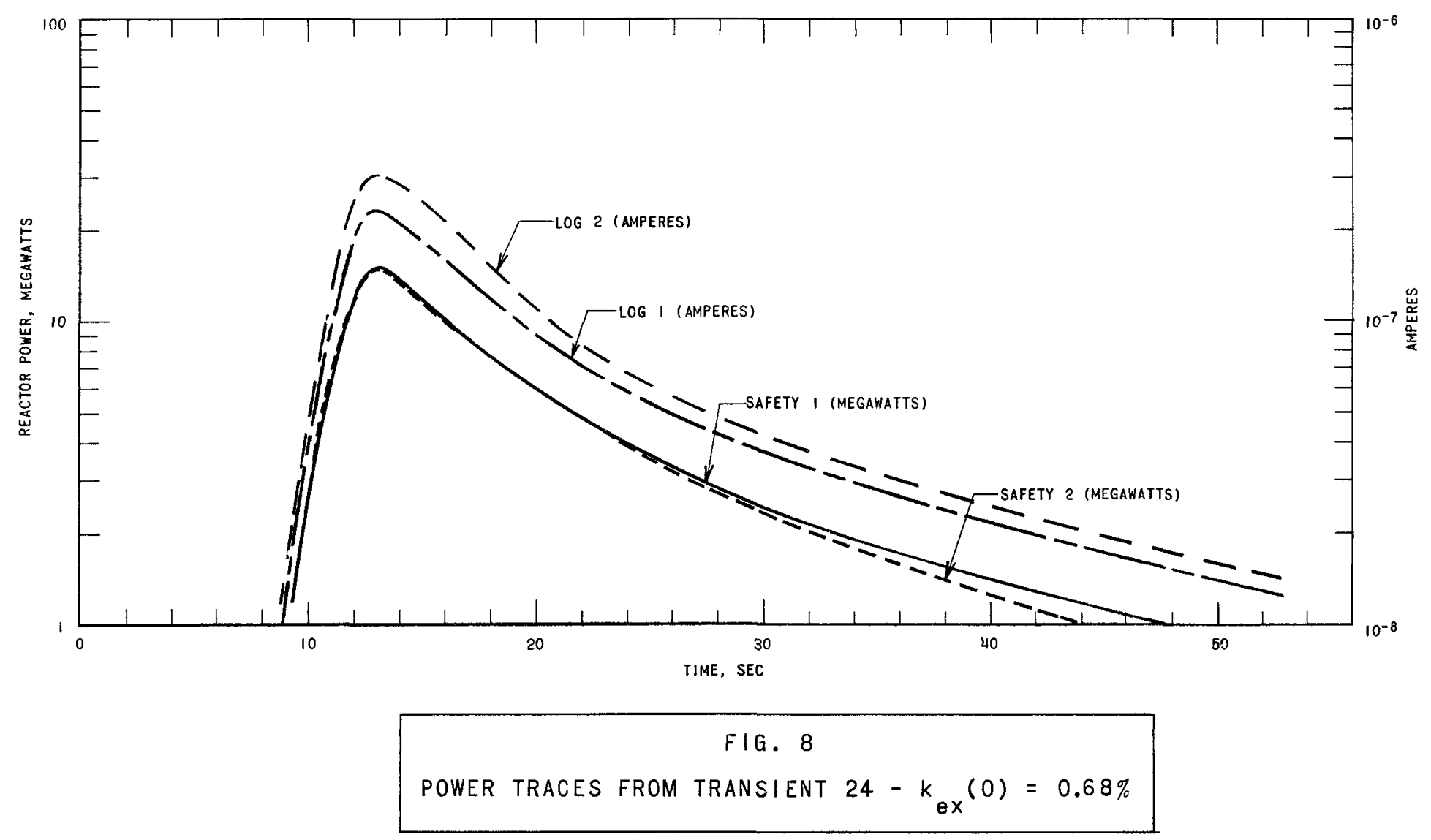




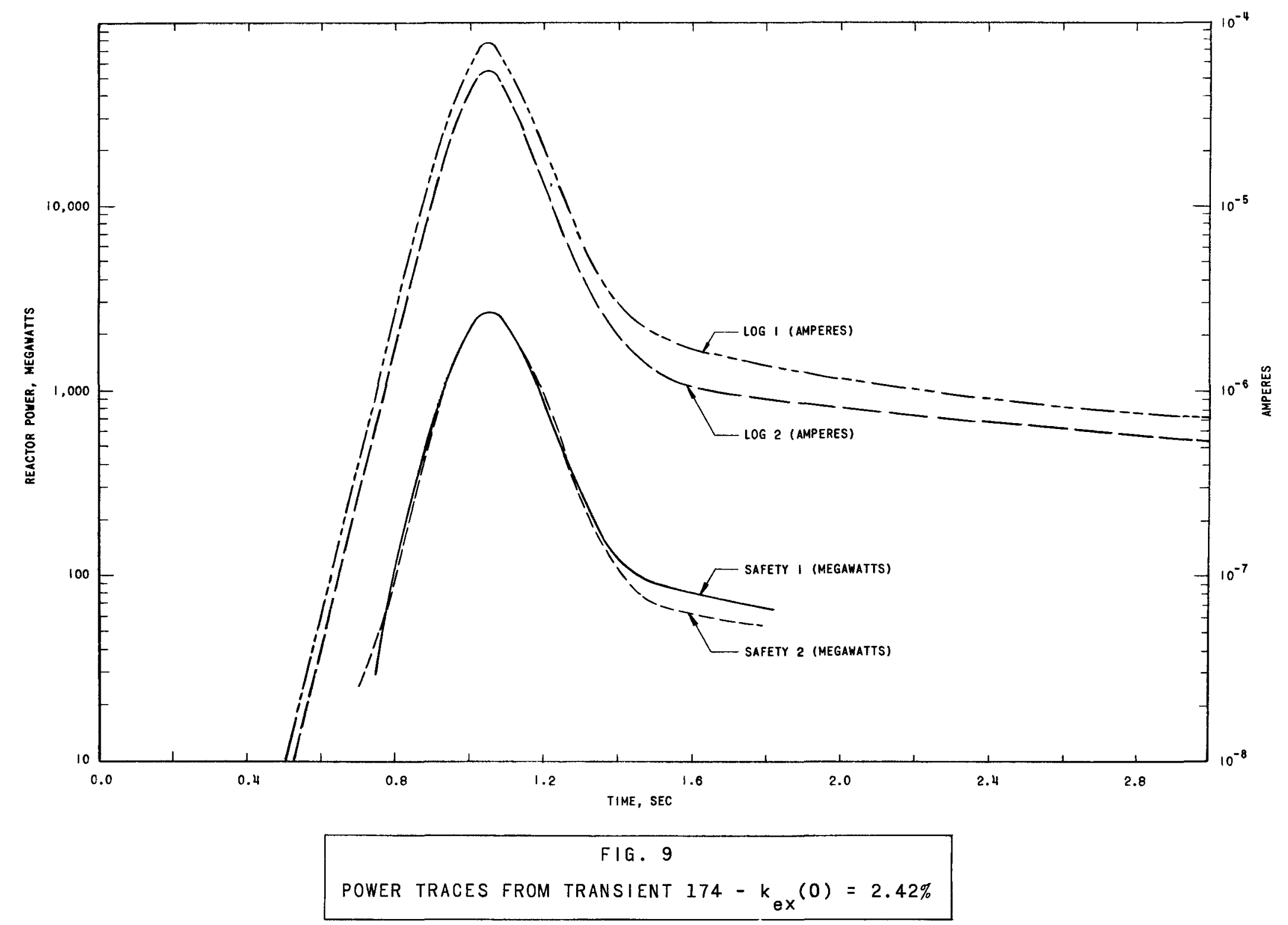




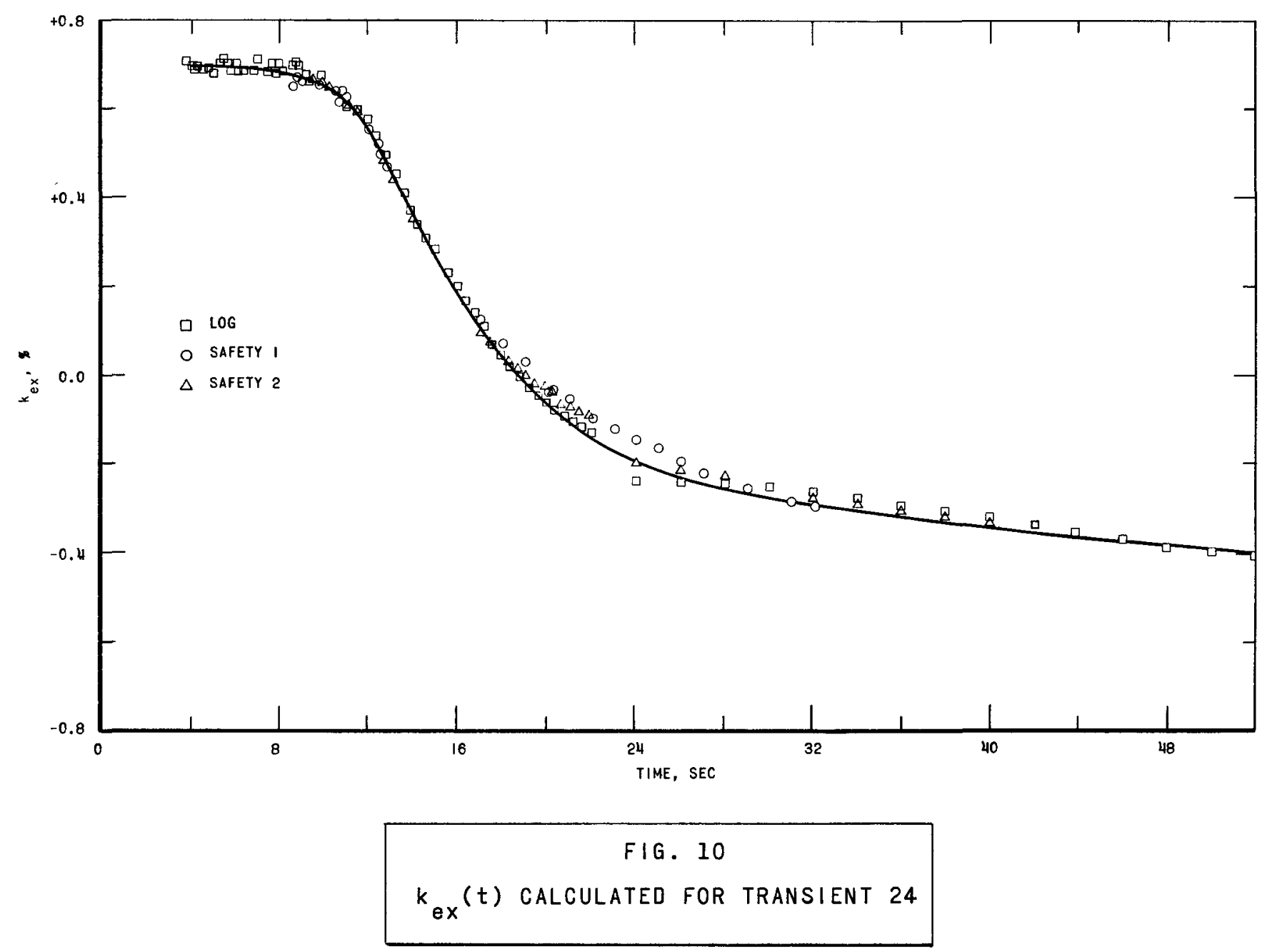




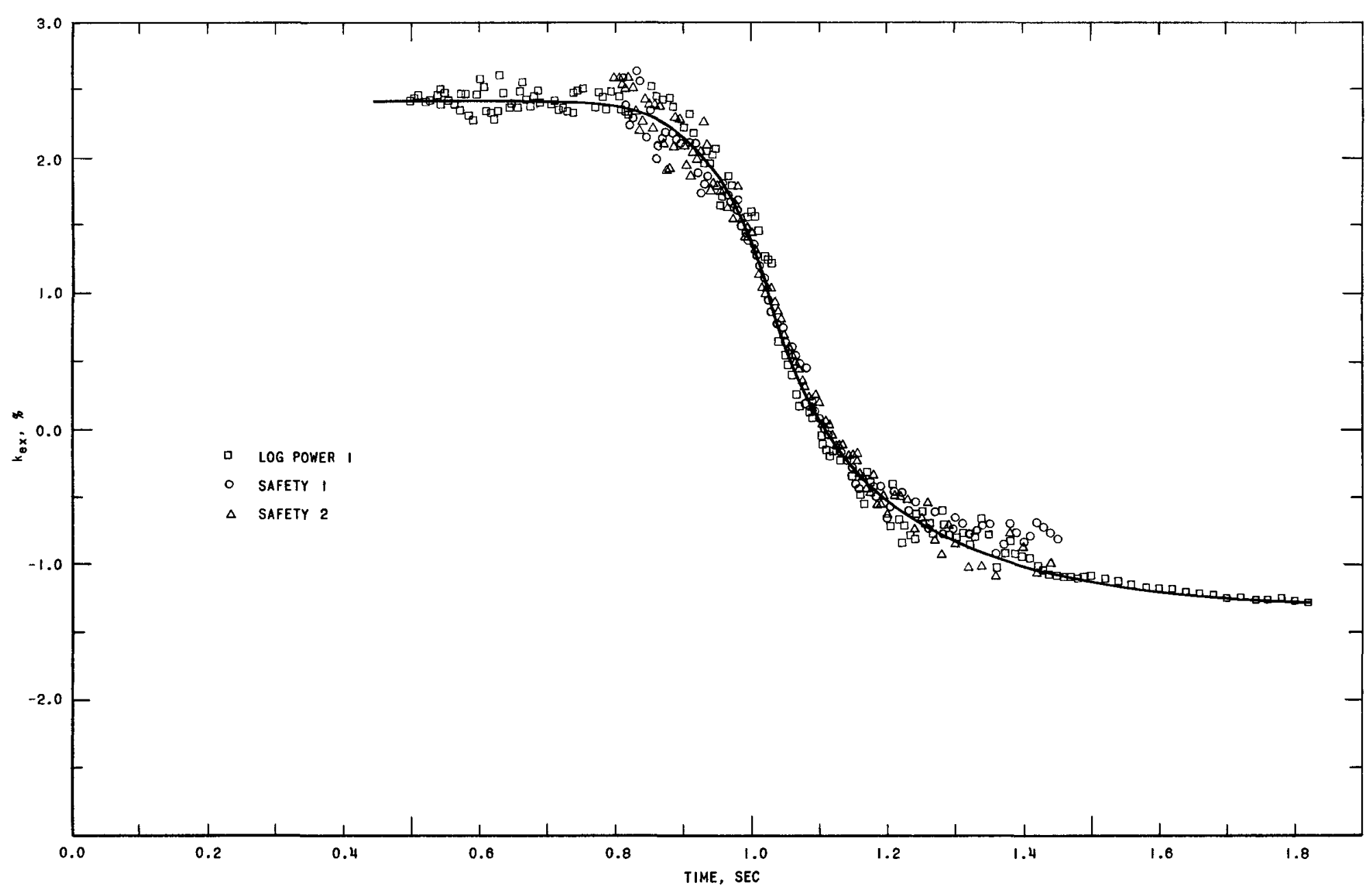

FIG. II

$k_{e x}(t)$ CALCULATED FOR TRANSIENT 174 
B. Theoretical Calculations

\section{Feedback}

Results of calculations of the temperature coefficient of reactivity for a TREAT-1ike reactor have been reported previously. $(3,4,5,7)$ Figure 12 displays the temperature coefficient of reactivity as a function of temperature for a spherical TREAT reactor with a reflector of averaged composition, an isothermal core, and a reflector at $300^{\circ} \mathrm{K}$. Multigroup diffusion theory, employing a 20 -group set of cross sections with a single fast group down to $2 \mathrm{ev}$ and the gas model for energy exchange between graphite and neutrons within the remaining 19 groups, was used. (7)

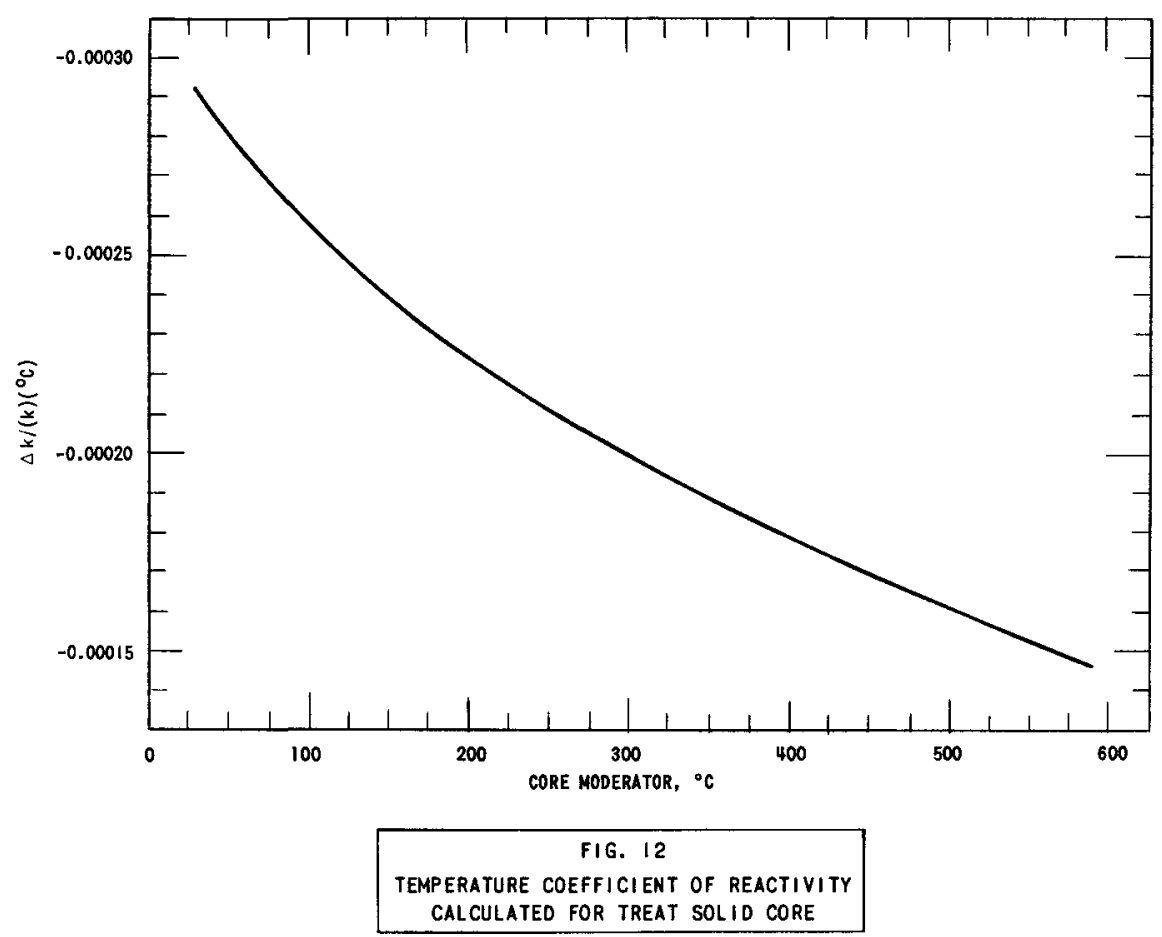

Curves of integrated neutron density vs kex were derived from that of Fig. 12 by use of experimental data for TREAT fuel enthalpy, a Maxwellian thermal spectrum, a fission cross section of $582 \mathrm{~b}$, and a value of $173 \mathrm{Mev}$ for the effective energy release per fission during each transient. Four curves of the integrated-neutron-density feedback relationship are shown in Fig. 13:

(1) a curve derived directly from that of Fig. 12;

(2) the normalized feedback relationship adopted for the solid core on the basis of the results of the kinetics experiments on that loading; $(7)$ 
(3) the feedback relationship obtained by normalizing the solid-core feedback to give general agreement with the maximum reactor power from the slotted-core meltdown transients;

(4) a curve calculated under the assumption of a constant temperature feedback of

$$
\frac{\mathrm{dk}_{\mathrm{ex}}}{\mathrm{k}_{\mathrm{eff}}}=-2.5 \times 10^{-4} \mathrm{dT}
$$

This last curve is not straight because the specific heat of the fuel is not constant. Implied in the direct conversion from temperature to integrated neutron density are the following assumptions:

(1) Heat transfer from the urania fuel particles to the graphite heat sink is essentially instantaneous.

(2) No appreciable heat is lost from the core during transients.

(3) No appreciable redistribution of temperature occurs in the reactor during transients.

(4) The fission cross section is $1 / v$ over the temperature range of interest.

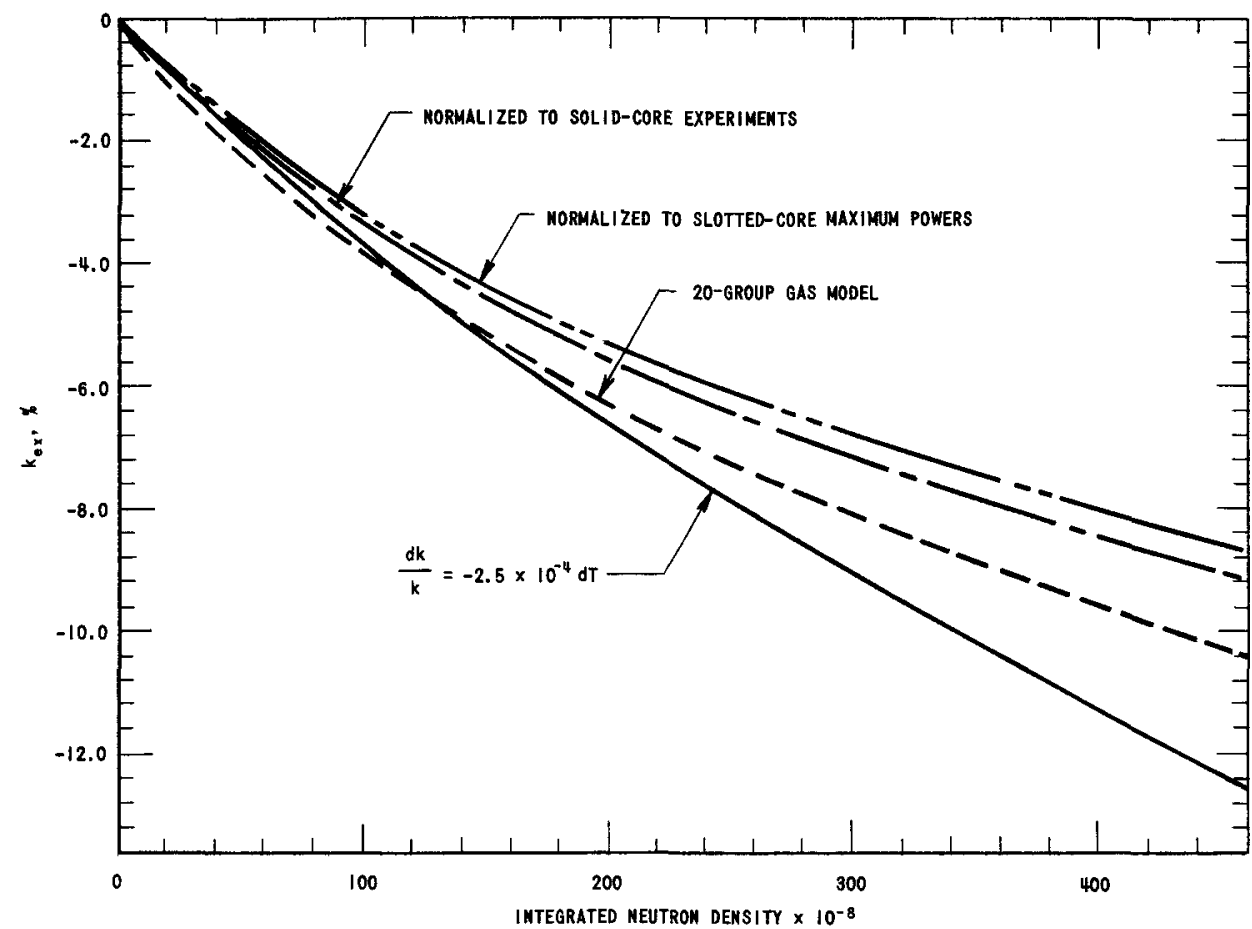

FIG. 13

$k_{\text {ex }}$ VS INTEGRATED NEUTRON DENSITY RELATIONSHIP 
The time constant for heat transfer from the urania fuel particles to graphite has been estimated, under conservative conditions, to be $1.8 \mathrm{~ms} .{ }^{(5)}$ Figure 14 shows the temperature traces for 2 core thermocouples after typical transients initiated with $0.68 \%$ and $1.63 \% \mathrm{kex}$, with the reactor loaded to include slot, dummy experimental element, and encapsulated samples. These curves demonstrate that, even with the large openings into the core and the resulting enhancement and complexity of paths for cooling air, no appreciable heat energy is redistributed or lost on a time scale comparable with that of typical transients. It should be noted that the time response of the core thermocouples shown in Fig. 14 is typical for all the reactor thermocouples, and is much too slow to show a time lag of the order of a few milliseconds.

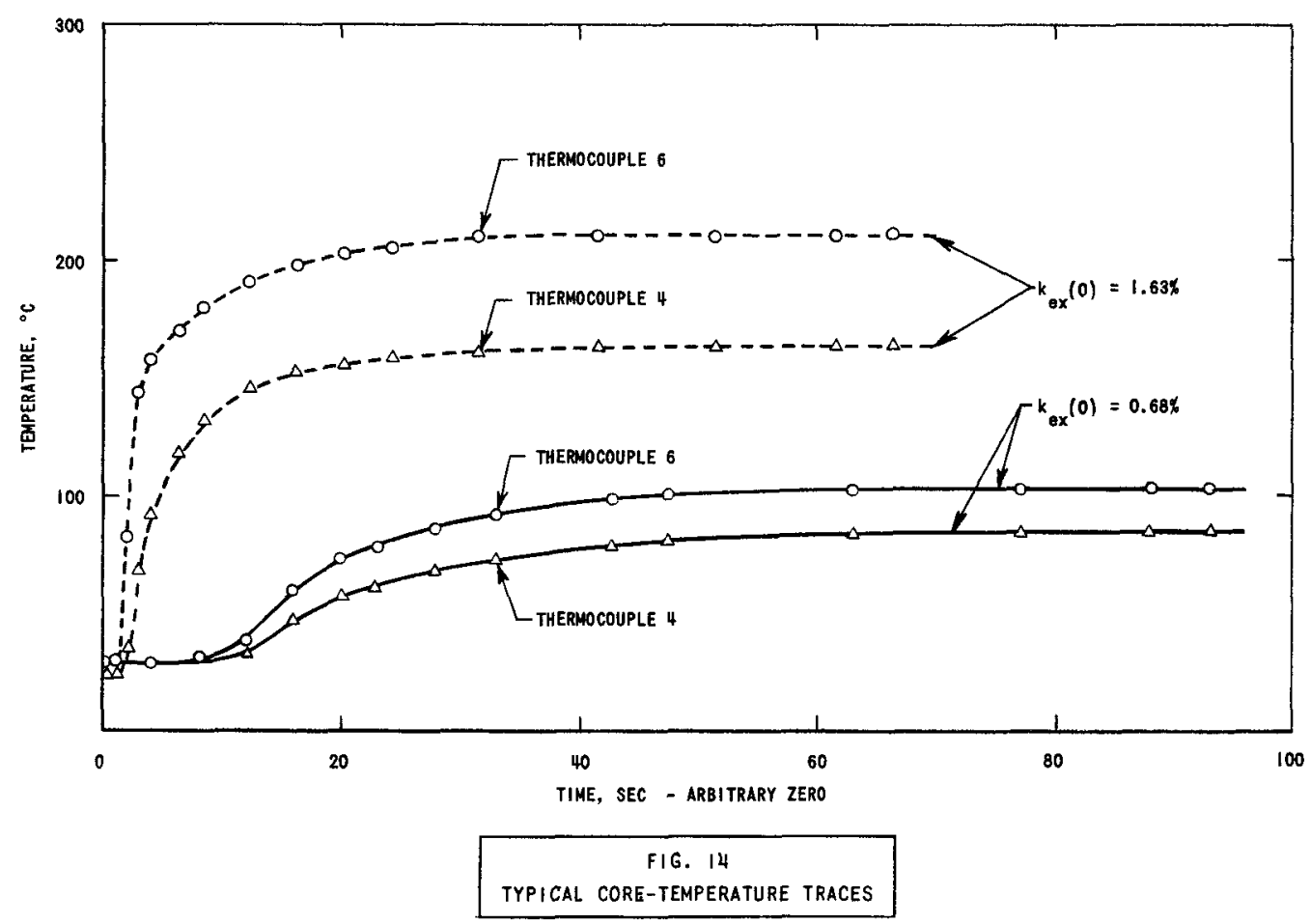

2. Calculation of $n(t)$

Neutron density as a function of time was calculated for theoretical transients corresponding to the experimental transients by means of the Argonne IBM-704 kinetics code RE-129.* This code complements $R E-171$ and solves for $n(t)$, given input parameters specifying $k_{e x}(t)$. Two RE-129 options are pertinent to this study:

$$
\begin{aligned}
& 129 \mathrm{C}: \quad k_{e x}(t)=k_{e x}(0)+A t+B \int n d t \\
& 129 H: \quad k_{e x}(t)=k_{e x}(0)+\sum_{i} A_{i} t^{i}+\sum_{i} B_{i}\left[\int n d t\right]^{i},
\end{aligned}
$$

*This is an IBM-704 version of the AVIDAC code RE-29. (13) 
where the $A, A_{i}, B$, and $B_{i}$ are constants and $i$ ranges from 1 to 4 . The simpler code $129 \mathrm{C}$ was used for the initial surveys of $n(t)$ and $\int \mathrm{ndt}$ as a function of initial $\mathrm{k}_{\mathrm{ex}}$ for purposes of specifying the reactor settings for meltdown experiments, and correlating and smoothing the early reactor kinetics results. As more data were made available and it became appropriate to phase in consideration of the actual nonlinear reactor $\mathrm{k}_{\mathrm{ex}} \mathrm{vs} \int \mathrm{ndt}$ relationship, use was made of $\mathrm{RE}-129 \mathrm{H}$. The constants $A$ and $A_{i}$ provide a convenient means for specifying reactivity changes due to control rod motion; the constants $\mathrm{B}$ and $\mathrm{B}_{\mathrm{i}}$ allow one to program calculations in which the reactivity feedback varies as that of a TREAT-like reactor. Provision is made in both versions for changing $A$ and $B$ (or the $A_{i}$ and $B_{i}$ ) at preset points in the course of calculations.

Values of $B_{i}$ for the theoretical feedback relationship were obtained by fitting the curve shown in Fig. 12 to the fourth-order $B_{i}$ relationship by least squares. Similarly, values of $A_{i}$ which approximated the $k_{\text {ex }}(t)$ changes due to rod motion were obtained for each specific case, as needed, by folding the rod-calibration curve and curves of control-rod position as a function of time, then fitting the resulting $k_{e x}(t)$ curve to the fourth-order $A_{i}$ polynomial by least squares. Two types of rod motion were reproduced: the regular shutdown scram motion used to terminate transients, and the slow-scram mode of operation by means of which it was possible to remove slowly control-rod poison from the reactor core over a time of the order of seconds, and thus sustain the reactor power (the "flat-top" type of TREAT power transient).

\section{Reactor Power Calculations}

Calculated values of $n(t)$ were converted into specific reactor power by means of the equation $(7)$

$$
P_{\mathrm{s}}=K_{\mathrm{p}} \mathrm{n},
$$

where $P_{S}$ is the specific average reactor power in units of megawatts per TREAT fuel element, and $K_{p}$ is a conversion factor defined by

$$
\begin{aligned}
\mathrm{K}_{\mathrm{p}}= & \frac{\text { number of } \mathrm{U}^{235} \text { atoms }}{\text { fuel element }} \times \sigma_{\mathrm{f}}^{25} \\
& \mathbf{x}\left(2.2 \times 10^{5} \frac{\mathrm{cm}}{\mathrm{sec}}\right) \times \frac{\mathrm{Mw}}{\text { fission }} \\
= & 3.232 \times 10^{-10} \frac{\mathrm{Mw}-\mathrm{cm}^{3}}{\text { element-neutrons }} .
\end{aligned}
$$

Conversion from specific power to reactor power was made by multiplying $\mathrm{P}_{s}$ by $\mathrm{N}_{e}$, the "effective" number of fuel elements in the core. 
In typical use, the reactor contains more fuel than is necessary to supply the $k_{\mathrm{ex}}(0)$ for each experiment, and the excess kex is held down by control rods. The effective number of elements is a function of reactor loading and initial $\mathrm{k}_{\mathrm{ex}}$; the relationship used for analysis of the reactor performance for these meltdown experiments is shown in Fig. 15.* Calculations of core size vs $k_{\text {ex }}$ by Schoeberle ${ }^{(14)}$ were normalized to reactor measurements in order to obtain the curve.

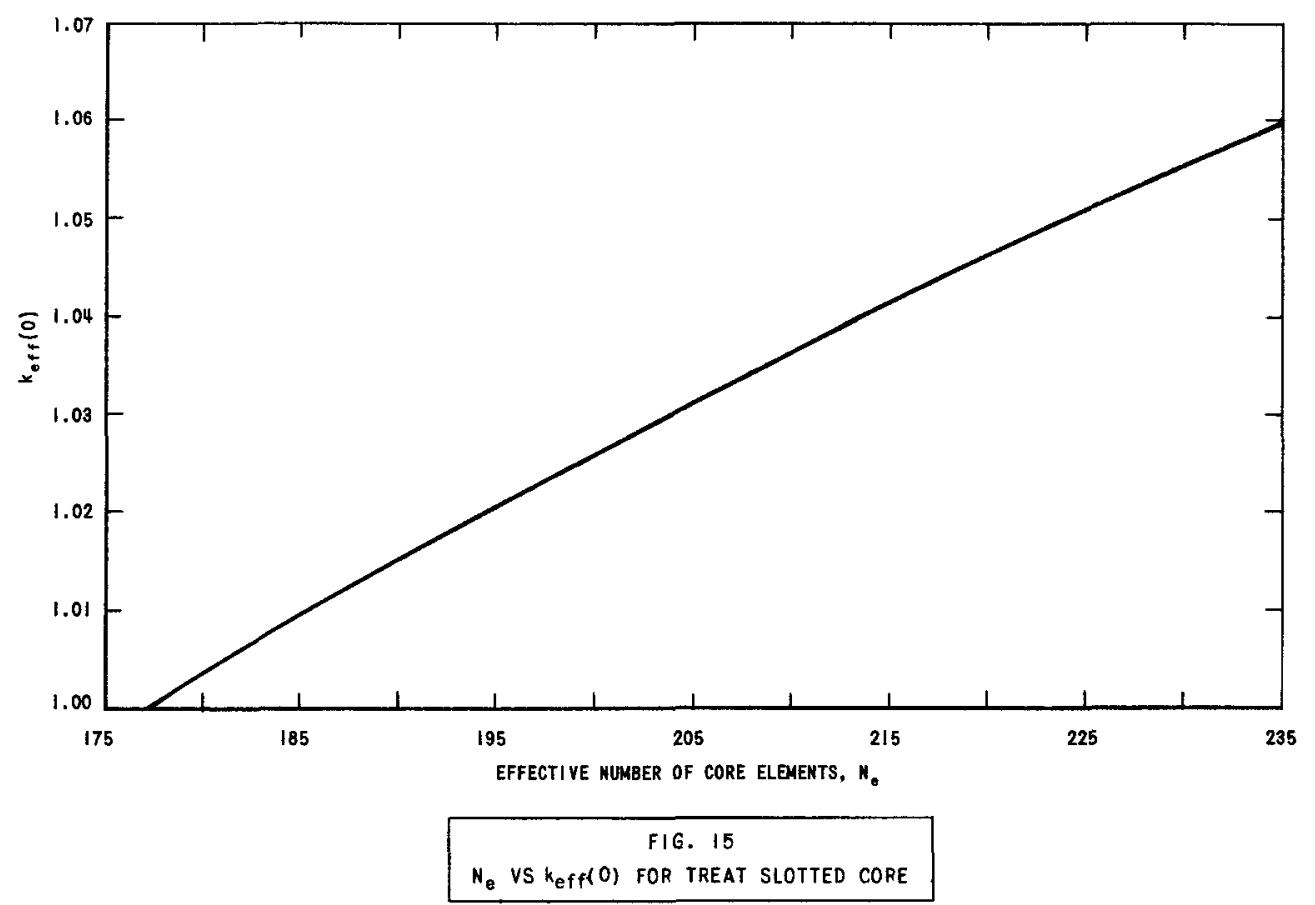

For a given value of $\mathrm{k}_{\mathrm{ex}}$, the value of $\mathrm{Ne}_{\mathrm{e}}$ for the slotted reactor is about $27 \%$ greater than that of the simple solid-core loading. In order to minimize discrepancies in calculations of total reactor power from the kinetics calculations of $n(t), 2$ slotted fuel elements were assumed to be equivalent to a standard fuel element.

Total calculated integrated power for a transient was obtained by taking the integrated power value calculated directly from the relevant $\mathrm{n}(\mathrm{t})$ computation and multiplying by $182 / 173$ to include the estimated $9 \mathrm{Mev}$ per fission additional energy release occurring due to fission product decay.

\section{Normalization}

Calculated power values were normalized to experimental data by the method described previously. (7) This technique preserves the shape of the power curve and is equivalent to multiplying the power values by a constant. Hence, the ability of a given feedback relationship to reproduce a given burst shape could be checked independently of checking the feedback absolute normalization.

*In. Fig. 15 is plotted initial keff against $\mathrm{Ne}_{\mathrm{e}}$; $\mathrm{k}_{\mathrm{eff}}=1+\mathrm{k}_{\mathrm{ex}}$. 


\section{COMPARISON OF EXPERIMENT AND CALCULATIONS FOR TREAT TEMPERATURE-LIMITED TRANSIENTS}

A. Definition

TREAT temperature-limited transients are defined here as being power excursions which attain maximum powers limited only by the negative temperature coefficient of reactivity and which show an appreciable power decrease before insertion of scram rods. Some flexibility is implied by this definition. In the case of study of maximum powers of temperature-limited transients, any transient scrammed after maximum power has been reached is of interest. In comparing experimental burst durations and peak shapes with the predictions of theory, transients scrammed after the power has decreased below half the maximum are "temperature-limited." And, finally, the most complete comparison between experiment and theory of the overall burst shape and intensity of the power tail following the peak requires that scram must occur at a time equivalent to several initial periods after the maximum power.

\section{B. Direct Comparisons}

\section{Calculated and Experimental Feedback}

Values of $\Delta \mathrm{k}_{\mathrm{ex}}$ as a function of integrated neutron density were obtained for selected points from the 5 transients referred to in Section II.A.2.,

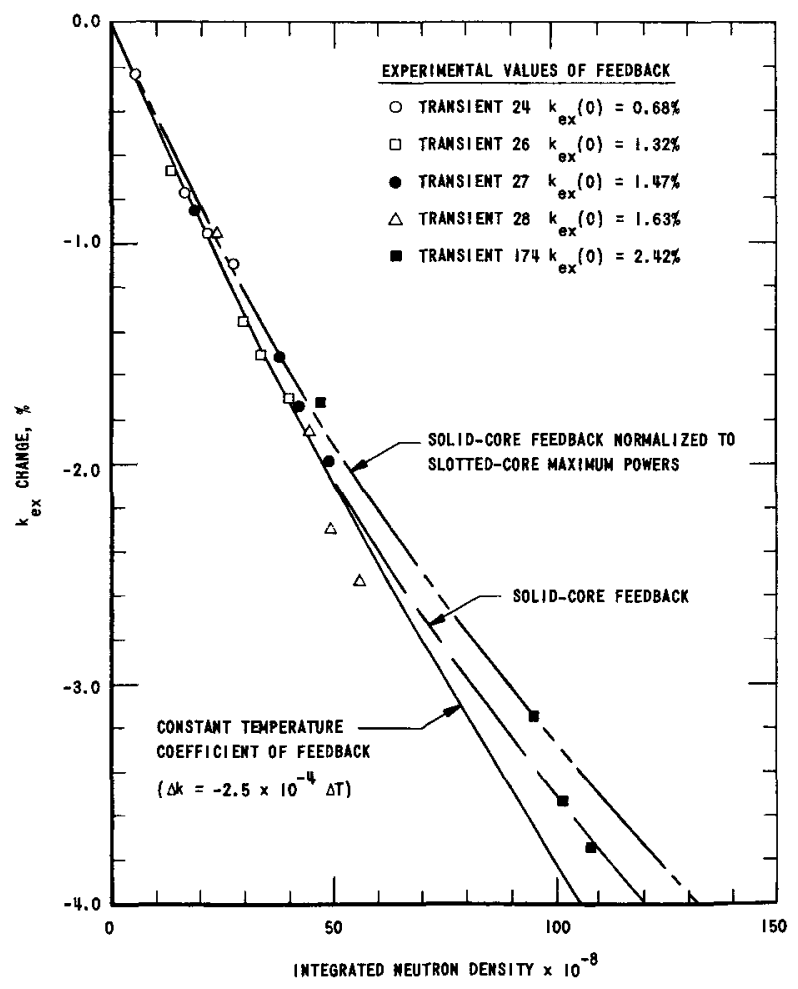

FIG. 16 COMPARISON OF EXPERIMENTAL FEEDBACK DATA \& FEEDBACK CURVES and compared with the calculated feedback curves of Fig. 13. The resulting agreement between the smooth, normalized solid-core feedback and the scattered, experimental feedback data points suggested that good general agreement between calculations and experiment could be obtained by means of this feedback relationship. Figure 16 shows the experimental feedback data from the 5 transients used for this analysis: the normalized solid-core feedback; the solid-core feedback normalized to fit the experimental slotted-core maximum power data; and the constant feedback curve of $\Delta \mathrm{k}_{\mathrm{ex}}=-2.5 \times 10^{-4} \Delta \mathrm{T}$, a simplified form of Eq. 6 introducing a negligible error for this range of $\mathrm{k}_{\mathrm{ex}}$. In order to afford a consistent comparison, all data were corrected to a core starting temperature of $30^{\circ} \mathrm{C}$. 


\section{Maximum Transient Power}

Experimental values of maximum transient power for temperature-limited excursions are shown in Fig. 17 as a function of initial $k_{e x}$. Power values were obtained by averaging the maximum readings of the linear power instruments. Shown in the figure for comparison is the calculated curve obtained on the basis of an initial core temperature of $30^{\circ} \mathrm{C}$ and normalized solid-core feedback relationship. Also included is the calculated curve which assumes the same starting temperature, but normalizes the solid-core feedback relationship to give good general agreement with the slotted-core maximum powers. Suitable agreement was obtained by a 10\% reduction of the solid-core feedback relationship.* Both feedback relationships were adopted for correlating the experimental data, as both satisfactorily reproduce the shape of the experimental curves of transient power.

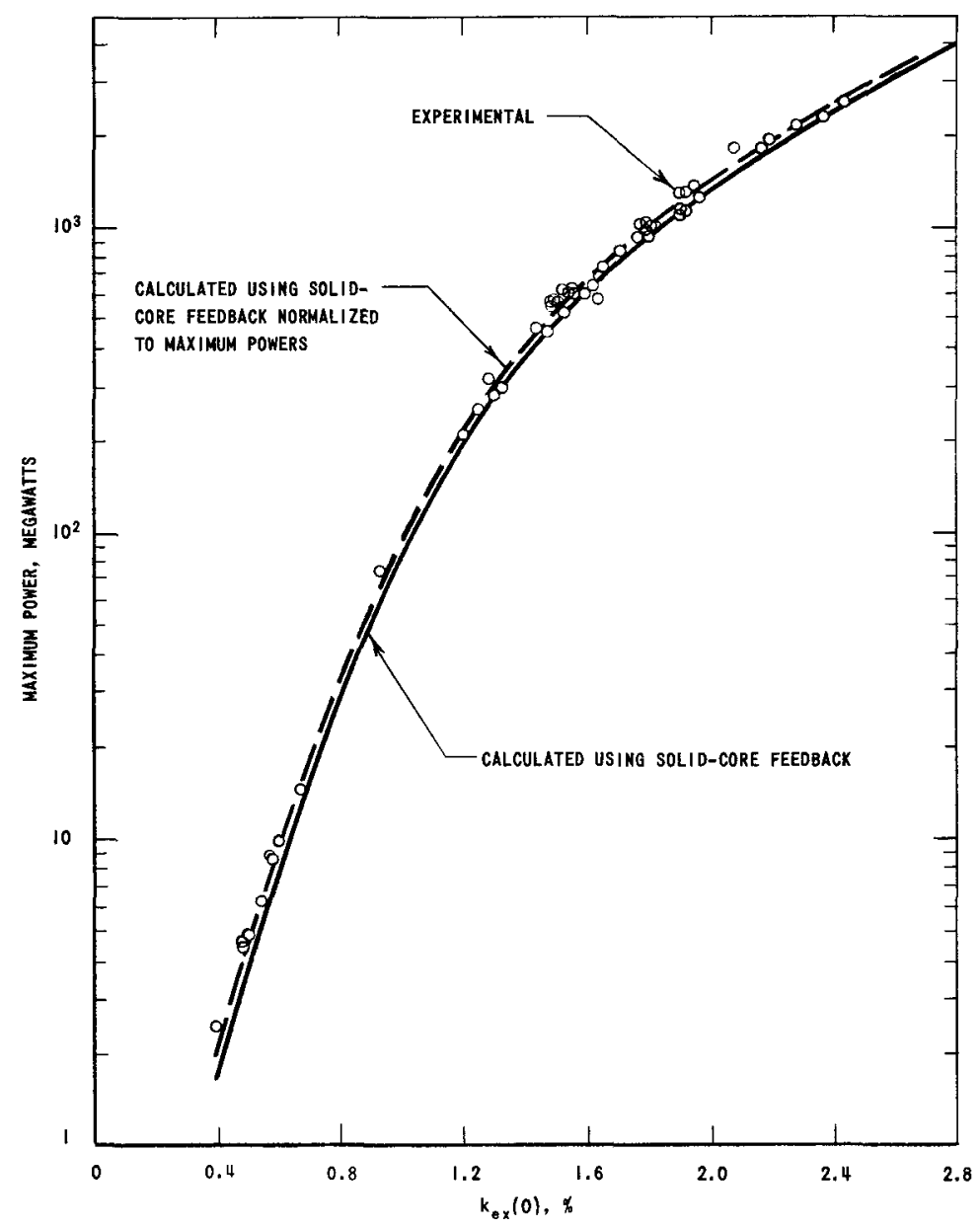

FIG. I7

COMPARISON OF CALCULATED ANO EXPERIMENTAL MAXIMUM TRANSIENT POWER

*As shown in Reference 7 , an equivalent increase of power level results. 

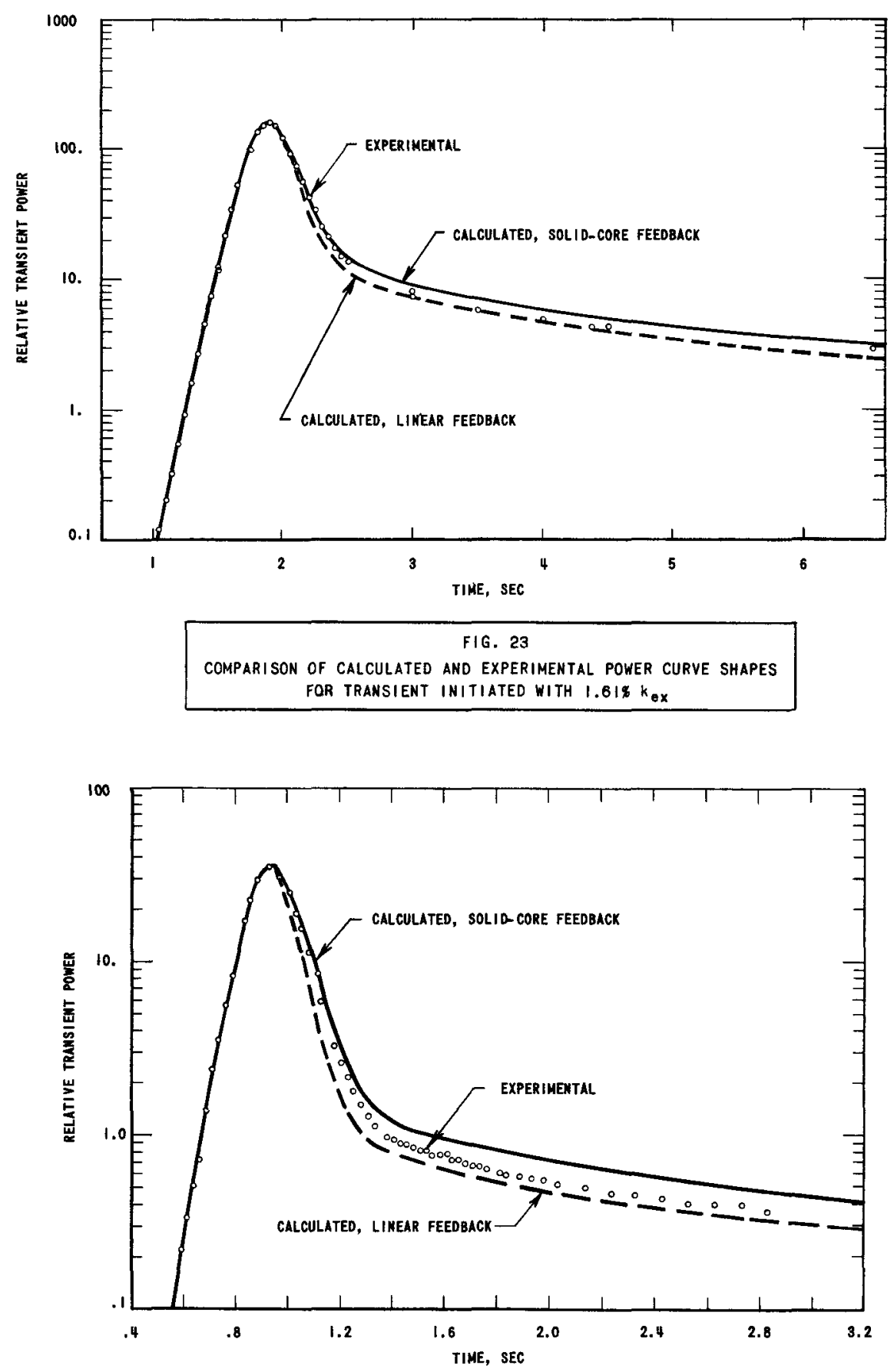

FIG. 24

COMPARISON OF CALCULATED AND EXPERIMENTAL POWER CURVE SHAPES FOR TRANSIENT IMITIATED WITH $2.42 \% k_{\text {ex }}$ 
The figures show that, although the calculated curves give a reasonable approximation of the experimental peak shape, agreement in the "tail" region beyond the peak is not as good. The 2 feedback functions yield power curves which usually bracket the experimental points. If the data indicate a general trend, it is that the linear feedback gives a slightly better tail shape. However, a significant portion of any such tendency could be due to uncertainties in the experimental calibrations.

Curve-shape indices are more convenient for checking curve shape if relatively large numbers of transients are concerned. For example, indices afford a quick means of testing the accuracy of an experimental power curve shape prior to using that shape for calculation of temperatures in a meltdown sample.(1) Figure 25 shows experimental values of a power peak width index, "peak half-width," from log power records as a function of $\mathrm{k}_{\mathrm{ex}}(0)$ obtained from the initial reactor periods. Also given in the figure is a curve from calculations made with the solid-core feedback. Power peak half-width is defined as the time between points of half-maximum transient power. A check of the decrease in reactor power after the peak is shown in Fig. 26, which displays the ratio of reactor power at a time one half-width after the maximum power to the maximum reactor power.

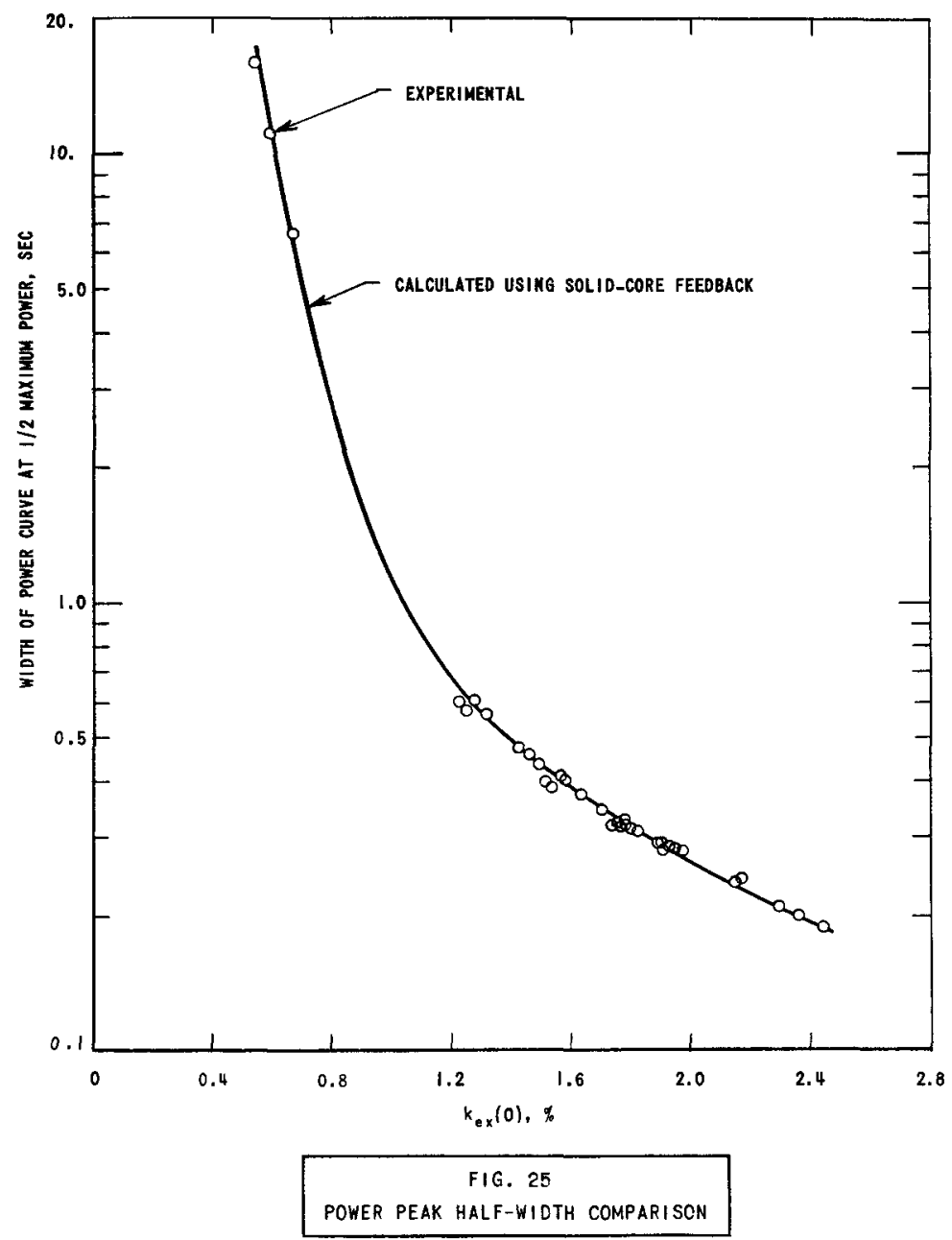




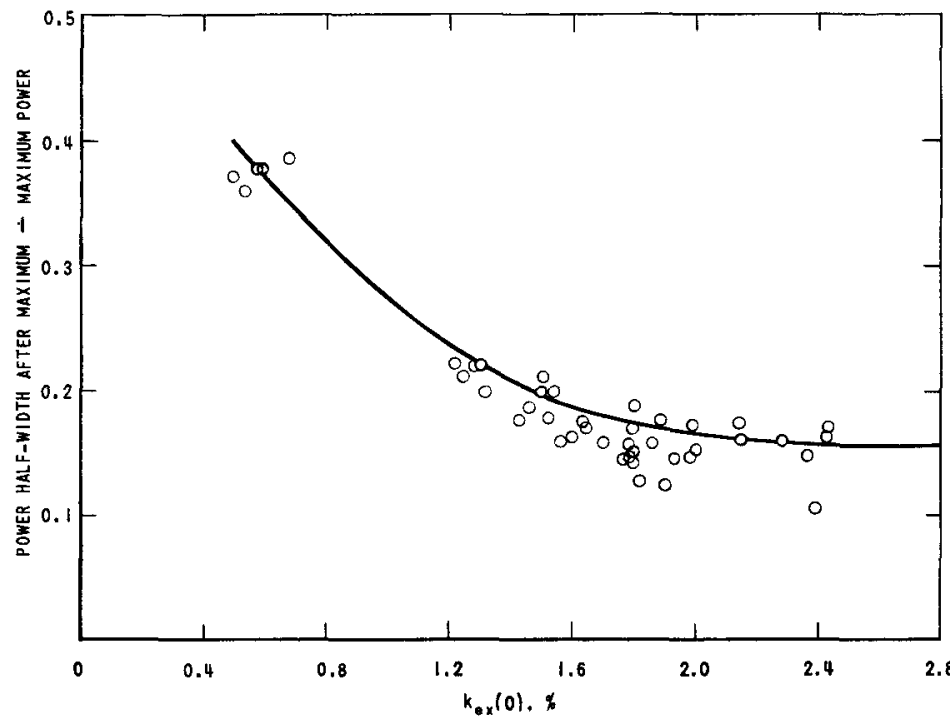

FIG. 26

COMPARISON OF POWER HALF-WIDTH AFTER MAXIMUM TRANSIENT POWER

Experimental points were taken from the log power traces and graphed as a function of $k_{e x}(0)$ obtained from the initial reactor periods. Included in Fig. 26 is a calculated curve obtained by means of the solid-core feedback. Both indices are of importance in testing a given power curve before using it for temperature calculations for a meltdown sample, since small inaccuracies in recorded calibration or recorder trace reading can introduce large changes in the magnitude of the power tail following the peak proper, or appreciably distort the peak itself. Distortions of the power curve, in turn, can materially change the calculated sample temperatures. For example, too large a proportion of the energy input occurring in the power tail would result in too small a calculated temperature rise, and thus a low maximum calculated temperature.

\section{Conclusions}

From the preceding survey of the temperature-limited kinetics of TREAT excursions with the slotted-core meltdown experiment loading, it would appear that the previously reported solid-core feedback relationship reproduces (within $\sim 10 \%$ ) the salient features of temperature-limited power peaks. Normalization of the absolute magnitude of the feedback relationship to obtain better agreement with the ensemble of maximum transient power data points was made by means of the technique followed in the study of the solid-core kinetics, (7) with the result that the normalized calculated curve shapes showed good agreement with experiment for maximum transient power and 2 criteria of peak shape. However, the detailed power curve shapes did not agree, in general, as well, Direct comparison of the calculated and experimental power curve shapes (see Figs. 21-24) showed the experimental power decreasing somewhat more 
sharply from the maximum than the calculated power obtained by means of the solid-core feedback. Experimental power tails were lower than calculated by means of the solid-core feedback. Similarly, experimental integrated power values were $\sim 5 \%$ lower than calculated by means of peak power-normalized solid-core feedback.*

No further normalization or fitting of calculation to experiment was attempted. In principle, changes might be made in the shape of the feedback relationship, prompt neutron lifetime, or $\beta_{\text {eff }}$. Since no good theoretical or experimental evidence exists for making such changes in an unambiguous fashion, and since the existing correlation appears to be satisfactory for a general description of the reactor behavior, the effects of such changes were not investigated.

Both the solid-core feedback and this feedback normalized to give good agreement on maximum transient power (see Fig. 13) were used in surveying reactor performance for specially programmed transients and higher integrated power values. In principle, the feedback normalized to maximum powers would be preferred for studies of TREAT behavior at power levels near the maximum, since such studies would be based on the output of the instruments used for that normalization.

* The magnitude of this effect is comparable to that expected from the deviation in power curve shapes after the maximum power. However, the magnitude of this effect is also comparable to experimental uncertainties. 


\section{SPECIALLY PROGRAMMED TRANSIENTS}

A. Clipped Transients

Reactor transients clipped by preset control-rod scram have been frequently employed in the meltdown experimentation. (1) Two principal types of clipped transients are of interest:

(1) transients which are scrammed during the initial exponential increase of power, and whose characteristics are determined by the initial period and the clipping $\mathrm{k}_{\mathrm{ex}}$ as a function of time.

(2) transients which are scrammed near or after the temperaturelimited power peak, and whose characteristics are determined by the time of scram, as well as by the initial period and the clipping $\mathrm{k}_{\mathrm{ex}}$ function.

Detailed specification of a clipped transient requires, in principle, the exact rod configuration at the time of scram [to provide the total $\Delta \mathrm{k}_{\mathrm{ex}}$ of the clip and the details of $k_{e x} v s$ time for the rod originally in the core to adjust total $\mathrm{k}_{\mathrm{ex}}(0)$ ], the exact pressure setting of the rod drives (to provide the time duration of the scram movement), and the exact time delay between the scram signal and the start of rod motion. In practice, these parameters were not constant, but most were found to be sufficiently uniform that general agreement was obtained between experiment and calculation by the use of one set of nominal clipping $k_{e x}(t)$ data. Only the time delay, which was found to vary in a random manner between zero and $100 \mathrm{~ms}$, could not be included in the nominal clipping $\mathrm{k}_{\mathrm{ex}}(\mathrm{t})$ function.

Figure 27 shows 2 experimental power curves for transients initiated with $1.5 \% \mathrm{k}_{\mathrm{ex}}$ and clipped before the temperature-limited peak. One is the Log 1 output for Transient 46, a typical experiment in the first meltdown series, which employed the clipped mode of operation. The other experimental curve is the Log 1 record from a later transient run after the original Mark I control drives (6) had been replaced by the more versatile Mark II rod drives. (15) Also shown is a calculated 1.5\% transient clipped at about the same place on the temperature-limited power curve as the experiments. The 3 curves have been normalized to the same maximum relative power to obtain the best possible comparison of curve shape. Reasonable agreement of the calculation with Transient 46 is obtained over the major portion of the curves. The apparent disagreement of the calculation and Transient 267 is partly the result of the experiment having been clipped somewhat nearer the temperature-limited peak than the calculation. 


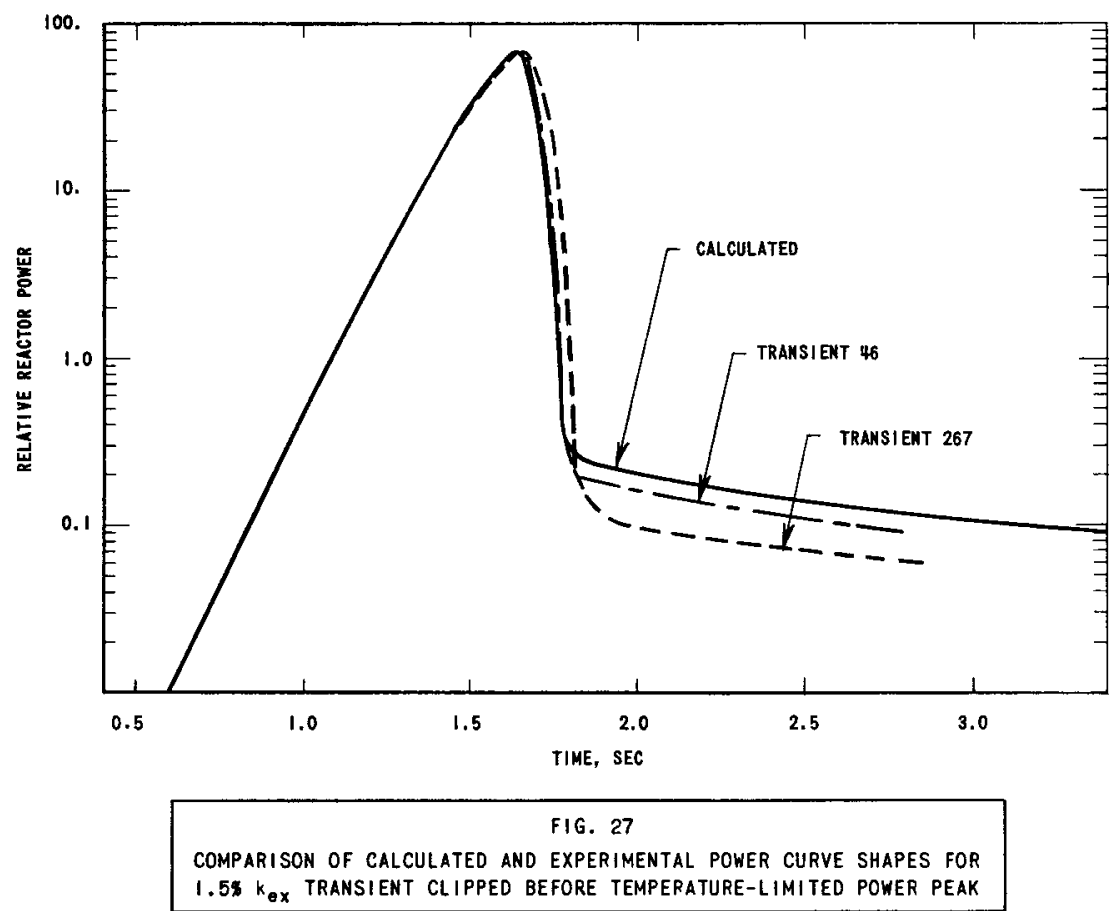

Figure 28 presents a family of curves calculated for transients of $1.5 \%$ initial $k_{\text {ex }}$ clipped near or after the temperature-limited power peak. The arrows locate the times at which the clip signals would have to be given to obtain these curves if a delay of $25 \mathrm{~ms}$ was assumed. The curves also demonstrate the dependence of the power curve half-width upon the power at the start of the control-rod motion.

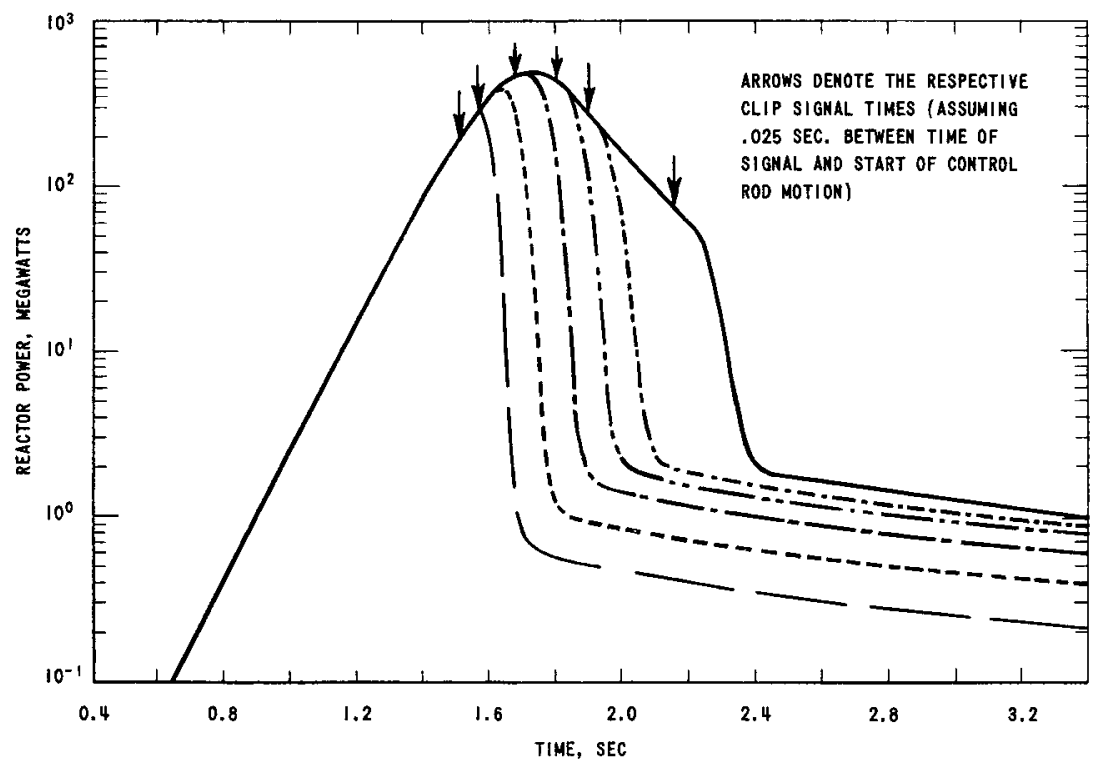

FIG. 28

CALCULATED REACTOR POWER VS TIME FOR 6 CLIPPED $1.5 \% k_{\text {ex }}$ TRANSIENTS 
The comparison of the half-widths of the experimental and calculated clipped transients constituted a further test of the accuracy of the nominal clipping $k_{e x}(t)$. Figure 29 illustrates this comparison. Three calculated curves of half-width are given as functions of initial $\mathrm{k}_{\mathrm{ex}}$. One assumed the clipping rod motion to begin on the initial exponential rise; the second assumed the clip began at one-half the temperature-limited maximum power; and the third assumed the clip began at the temperaturelimited peak. The half-widths of experimental clipped transients are also plotted in the figure. For convenience, the experimental points have been divided into 3 groups: those in which the transient attained a maximum power less than one-half the temperature-limited maximum; those in which the maximum power was greater than half, but less than equal to that of the temperature-limited peak; and those which attained a power, within experimental uncertainty, equal to the temperature-limited maximum for that $k_{\mathrm{ex}}(0)$. The figure indicates a good agreement between calculation and experiment. However, this comparison is independent of any delay time between the signal and start of the clipping motion.

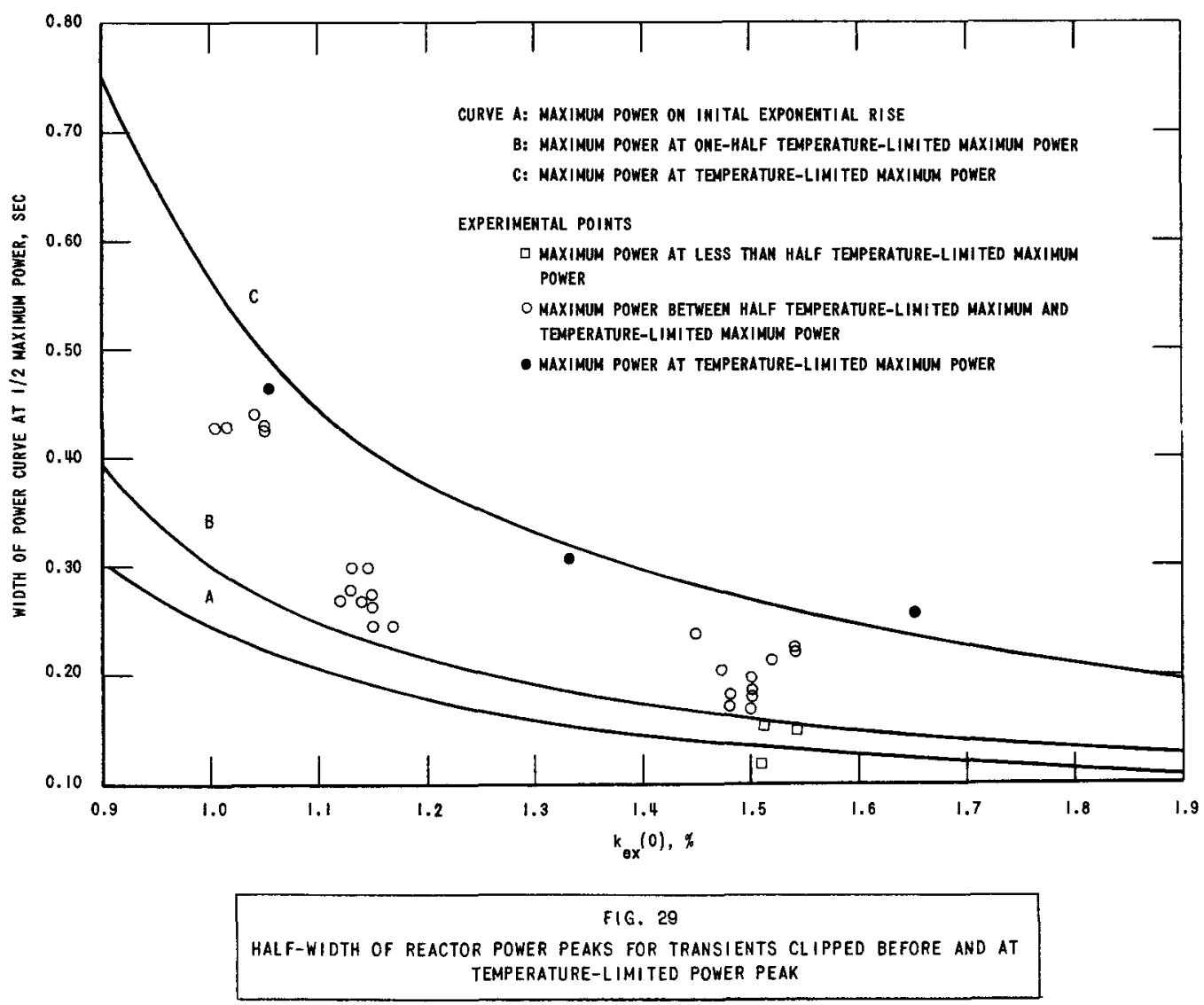

In Fig. 30 is plotted the ratio of integrated power at the clip signal to the total integrated power for the transient as a function of initial $\mathrm{k}_{\mathrm{ex}}$. The experimental points have been divided into the groups used in Fig. 29 , but are fewer in number, as the integrated power data were not always 
available. The total integrated power values have not been extended to a common final time; however, for no point shown should this correction exceed $5 \%$. The delay time and absence of the correction to common final time contribute to the experimental scatter. Three calculated curves are also shown. These correspond to calculations in which the rod motion began on the exponential rise, at half the temperature-limited maximum power, and at the temperature-limited peak, and with the clip signal preceding the rod motion by $50 \mathrm{~ms}$. A common final time of $60 \mathrm{sec}$ was used in the calculations. The 50-ms time delay has been found sufficient to place most of the experimental points in approximately the correct location between the curves for peak and half-peak power clips.

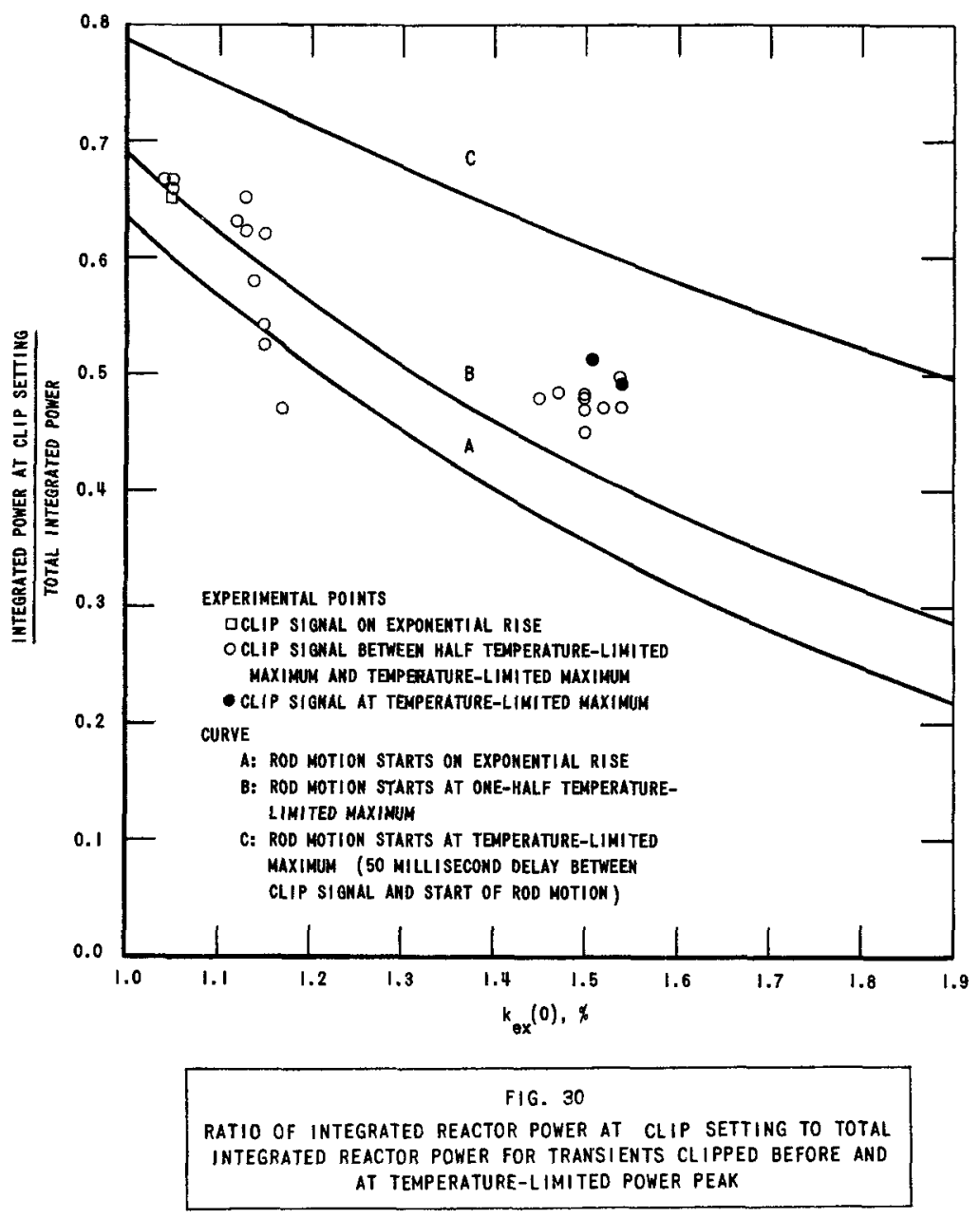

The effect of the time delay on the total integrated power of clipped transients initiated with $1.5 \% \mathrm{k}_{\mathrm{ex}}$ is illustrated more clearly in Fig. $3 \mathrm{l}$. Here the calculated total integrated power has been plotted as a function of the integrated power at the clip signal and various delay times. Curves are given for time delays of $0,25,50,75$, and $100 \mathrm{~ms}$. The calculated curves end at about $480 \mathrm{Mw}-\mathrm{sec}$, as this is the integrated power of a $1.5 \% \mathrm{k}_{\mathrm{ex}}(0)$ temperature-limited transient at $60 \mathrm{sec}$. Also given in the 
figure are experimental points for clipped transients initiated with $\mathrm{k}_{\mathrm{ex}}$ between $1.47 \%$ and $1.53 \%$. As in the previous figure, these points have not been corrected to a common $60-\mathrm{sec}$ final time, yet almost all lie well within the calculated envelope. The spread of the points also is an indication of the randomness of the delay time.

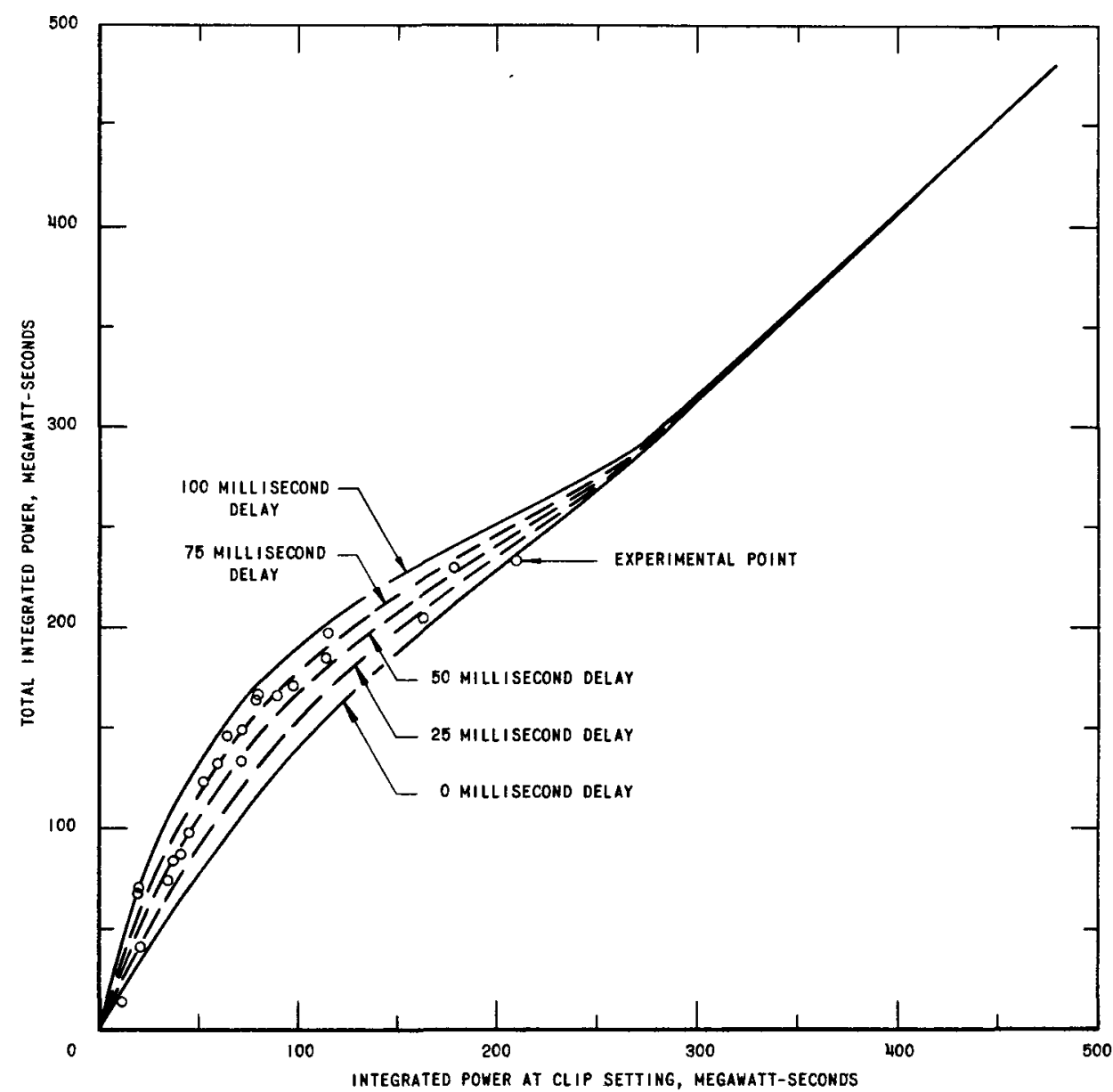

FIG. 31

TOTAL INTEGRATED TRANSIENT POWER AS A FUNCTION OF INTEGRATED POWER AT CLIP SETTING AND DELAY TIME FOR $1.5 \% \mathrm{k}_{\text {ex }}(0)$ TRANSIENTS

Figure 32 extends these results to clipped transients of other initial $\mathrm{k}_{\mathrm{ex}}$. In this case, the total integrated power has been plotted against the integrated power at the clip signal, with an assumed delay of $50 \mathrm{~ms}$, for transients with initial $\mathrm{k}_{\mathrm{ex}}$ of $1.1 \%, 1.5 \%$, and $1.8 \%$ The vertical bars give the variation to be expected in total integrated power for delay times between 0 and $100 \mathrm{~ms}$. Clipped transients of $1.1 \%$ and $1.5 \%$ initial $\mathrm{k}_{\mathrm{ex}}$ have been frequently used in the meltdown experimentation. (1) The curve for 
clipped transients of $1.8 \%$ initial $k_{e x}$ is included for comparison to indicate the properties of clipped transients with appreciably shorter initial periods.

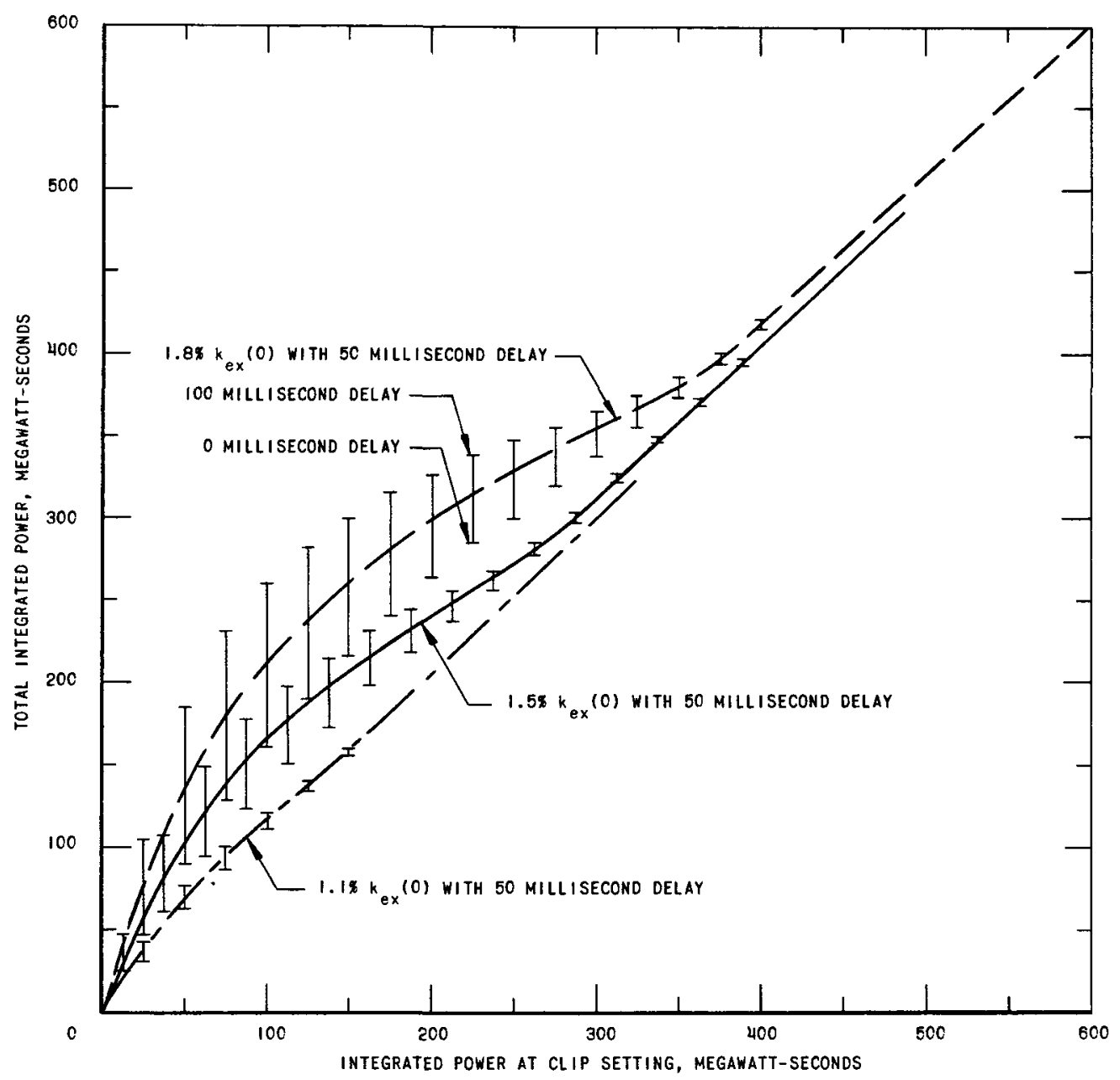

FIG. 32

TOTAL INTEGRATED TRANSIENT POWER AS A FUNCTION OF INTEGRATED POWER AT CLIP SETTING AND DELAY TIME FOR $k_{\text {ex }}(0)=1.1 \%, 1.5 \%, 1.8 \%$

B. Constant-power Transients

\section{General Characteristics}

Given knowledge of the reactor-kinetics properties for temperature-limited transients and the characteristics of the special "slow scram" mode of operation of the control-rod drives, (15) it becomes possible to determine the performance of constant-reactor-power transients. Such transients may be described in terms of 4 phases: 
(1) initial power rise on an exponential period;

(2) reduction of $k_{e x}$ until the time derivative of reactor power is zero*.

(3) sustaining neutron density at a constant level by addition of reactivity by control-rod motion to compensate for the negative temperature coefficient of reactivity;

(4) termination of the transient either by scramming the reactor, or by halting the sustaining rod addition and letting the negative temperature coefficient shut down the reactor.

Phase two may be accomplished either by a pre-programmed rod movement or by utilizing the negative temperature coefficient of reactivity of the reactor. The latter approach has been adopted for meltdown experimentation, (1) since it has so far provided sufficient experimental flexibility and places less severe demands on reactor-control operations.

In setting up specifications for a constant power transient, the reactor power level and total integrated power are first established. Next, the initial $\mathrm{k}_{\mathrm{ex}}$ corresponding to a temperature-limited peak power equal to the desired reactor power is determined from the normalized theoretical curve of Fig. 17. In turn, this $\mathrm{k}_{\mathrm{ex}}(0)$ defines:

(1) the integrated reactor power up to the start of the constant power portion of the transient;

(2) the $k_{e x}(t)$ for the constant-power transient.

The integrated reactor power to the temperature-limited peak may be obtained either from integration of the transient reactor power records, or from calculations. As indicated by the good agreement of experiment and calculations on power curve shapes (see Section III.C.) and the normalization to maximum transient power (see Section III.B.), calculation and experiment agree well on this point. Figure 33 is a comparison of calculated and experimental values of integrated power to the temperaturelimited peak as a function of initial $\mathrm{k}_{\mathrm{ex}}$. This figure demonstrates that, over a range of values of $\mathrm{k}_{\mathrm{ex}}(0)$ of interest experimentally for meltdown testing** (initial $\mathrm{k}_{\text {ex }}$ from 0.4 to $0.7 \%$ ), the integrated power to peak is

\footnotetext{
* In general, because of the delayed neutrons, the $k_{e x}$ at this time is not zero; it increases toward $\beta$ eff asymptotically as the initial period approaches zero.
}

** See Table III of Reference 1 . 
essentially constant at $\sim 30 \mathrm{Mw}-\mathrm{sec}$. Given the integrated power to peak, the duration of the constant-power portion of the burst can be fixed. Hence, for $k_{\mathrm{ex}}(0)$ in the range from 0.4 to $0.7 \%$, the duration of the constant-power portion is given approximately by

$$
D \sim \frac{T-30}{P_{t}},
$$

where $\mathrm{D}$ is duration in seconds, $\mathrm{T}$ is total integrated power desired in $\mathrm{Mw}-\mathrm{sec}$, and $\mathrm{P}_{t}$ is the temperature-limited peak power level in $\mathrm{Mw}$. For higher values of $k_{\text {ex }}(0)$, Fig. 33 is needed.

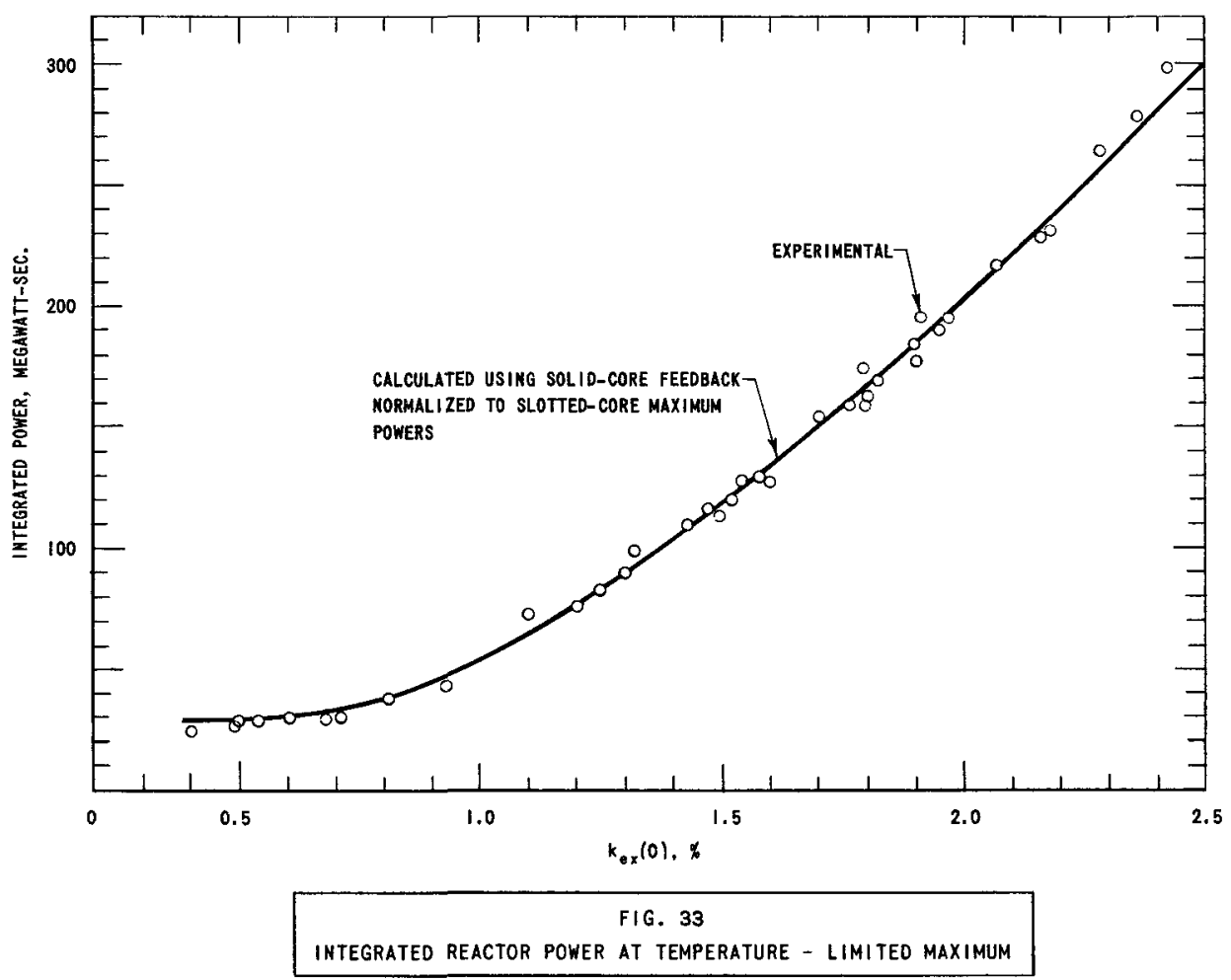

For an ideal, constant-neutron-density transient, the sustaining $\mathrm{k}_{\mathrm{ex}}$ is not equal to the change in $\mathrm{k}_{\mathrm{ex}}$ produced by the reactor temperature coefficient of reactivity. The sustaining $\mathrm{k}_{\mathrm{ex}}$ is somewhat smaller, since, during the course of the transient, the reactor $k_{e x}$ decreases asymptotically from its value at the time of the temperature-limited power peak to zero as the delayed neutron precursors approach equilibrium. This is illustrated in Fig. 34, which shows curves of $k_{e x}$ as a function of time calculated for a constant-power transient initiated with $0.50 \% \mathrm{kex}$. Calculations were extended well beyond the range of typical constant-power durations to display the asymptotic nature of the $k_{e x}$ necessary to sustain the constant-power level. For clarity, the sustaining $k_{\text {ex }}$ necessary to compensate for the heating of the reactor has been omitted from Fig. 34. Figure 35 shows the 
calculated sustaining $\mathrm{k}_{\mathrm{ex}}$ for the ideal constant-power transient of Fig. 34 . Both figures are typical of this sort of transient, except for time scale and $\mathrm{k}_{\mathrm{ex}}$ at the start of sustaining $\mathrm{k}_{\mathrm{ex}}$.

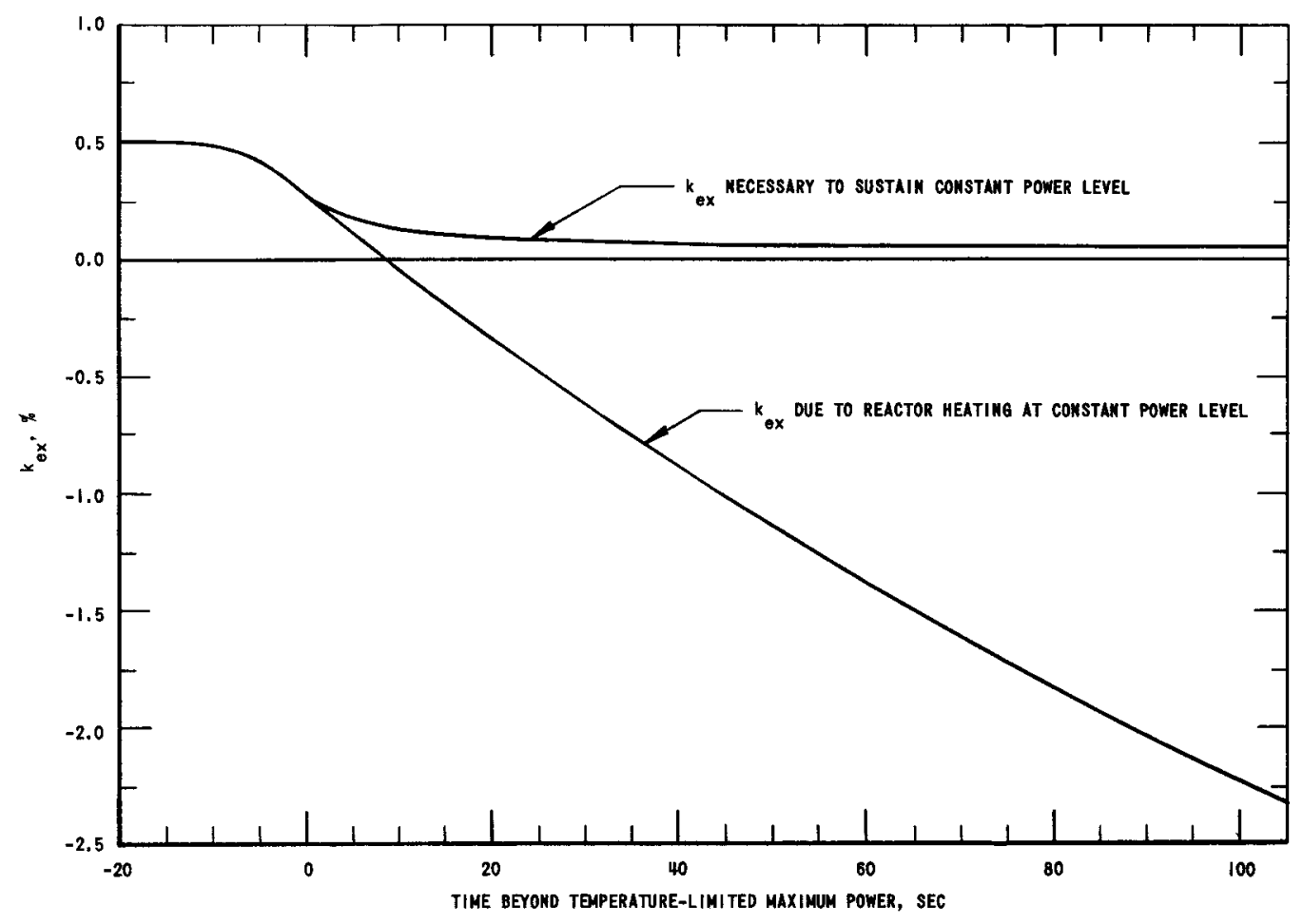

FIG. 34

CALCULATEO CURVES OF $k_{e x}$ VS TIME FOR $0.905 k_{0 x}(0)$ CONSTANT POWER TRANSIENT

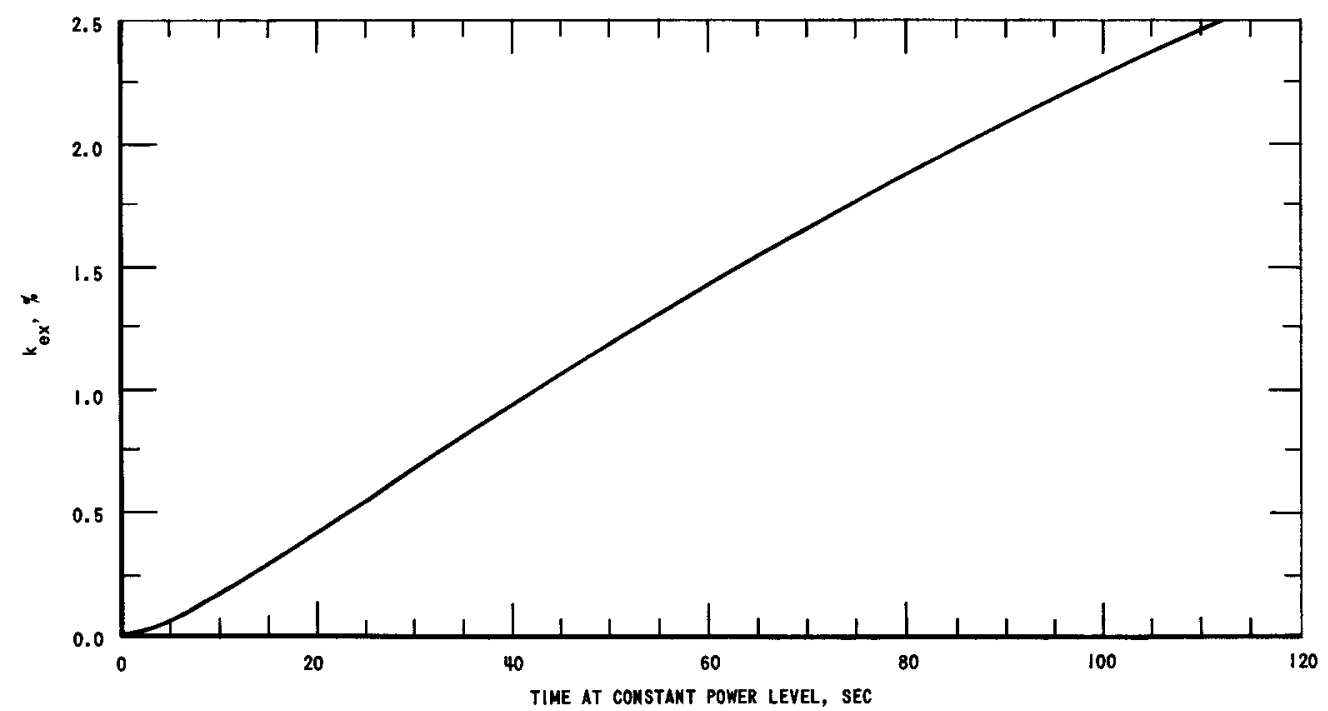

$F I G, 35$

CALCULATED SUSTAINING $k_{\text {ex }}$ VS TIME FOR $0.50 \% k_{e x}(0)$ CONSTANT-POWER TRANSIENT 
The calculated sustaining $k_{\text {ex }}$ curves for 5 ideal, constant-power transients with $k_{\text {ex }}(0)$ between 0.50 and $0.95 \%$ are displayed in Fig. 36 . The curves have been plotted with their respective temperature-limited peaks as time zero. Both the solid-core and slotted-core feedback relations yield the same calculated curve of $k_{e x}$ due to reactor heating if the corresponding value of constant-power level is used. This is due to a cancelation of the peak-power normalizing factor by an equivalent reduction in the feedback function. To a limited extent, the curvatures of the reactor temperature feedback and the ideal $\mathrm{k}_{\mathrm{ex}}$ curves cancel, giving nearly linear sustaining $k_{e x}$ curves over the duration and $k_{e x}(0)$ ranges of principal past interest for meltdown experiments.(1) Slopes of these curves are not proportional to the corresponding constant-power levels because of the nonconstant, nonzero $k_{\text {ex }}$ required during the constant-power region by the delayed neutrons.

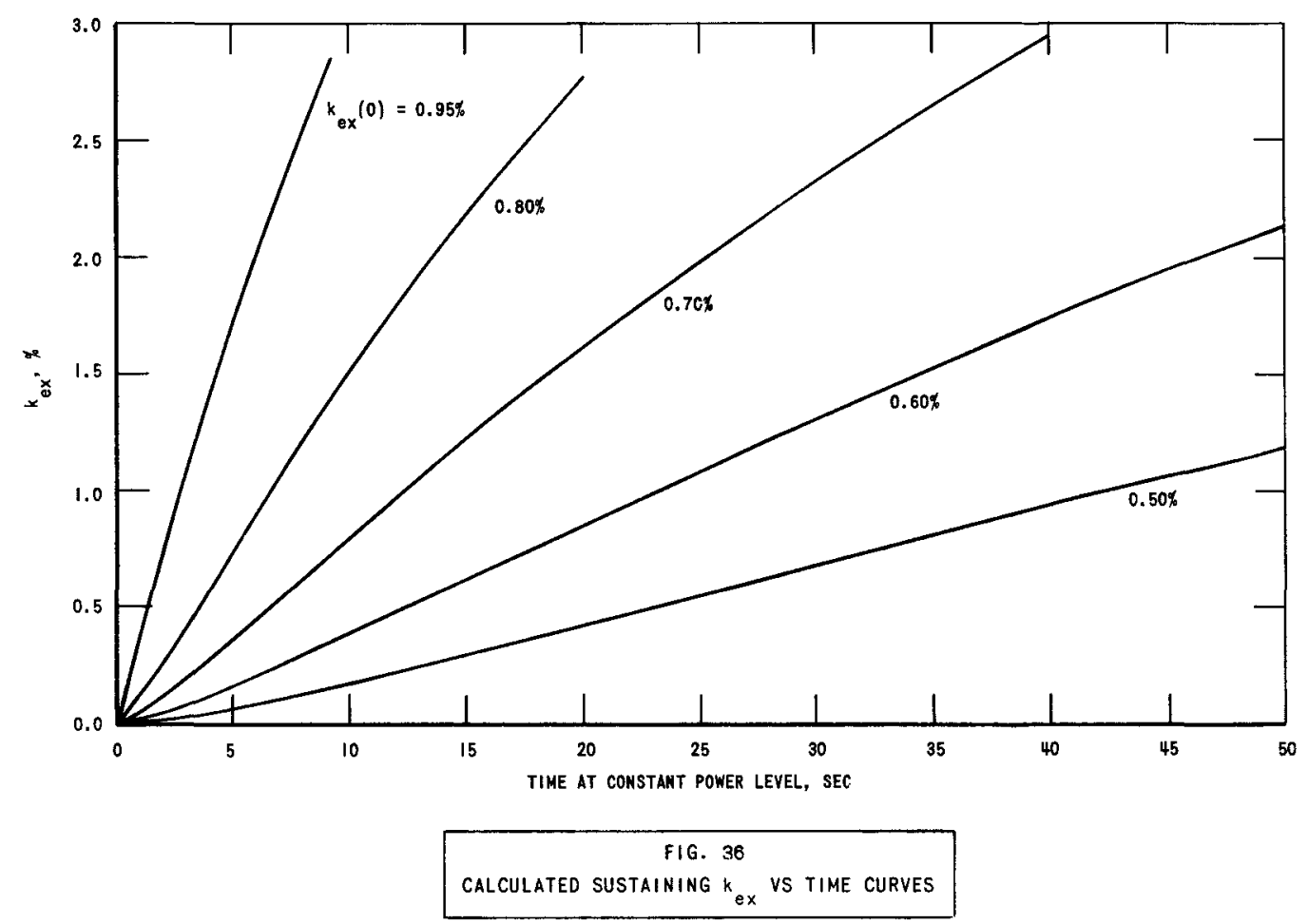

It should be noted that these sustaining $k_{\text {ex }}$ curves are based on the average neutron density in the reactor, not the reactor power. Hence, the curves apply to all constant-power transients initiated with the $\mathrm{k}_{\mathrm{ex}}(0)$ values shown, regardless of exact reactor loading and $\mathrm{N}_{\mathrm{e}}$ (or actual power level), as long as the reactor-kinetics behavior can be adequately represented by the slotted-core (or solid-core) meltdown experimental feedback relationship. Because of the small, $\sim 5 \%$, difference between experiment and calculations based on either the solid-core or the slotted-core feedback, these curves would appear to have rather general utility for constant-power TREAT experiments. 


\section{Limitations on Constant-power Transients}

Certain limitations may be placed on specifications of constantpower transients as a result of operating restrictions. The basic restriction is the current operating limitation of a $400^{\circ} \mathrm{C}$ maximum core temperature.* It is estimated that a maximum core temperature of $400^{\circ} \mathrm{C}$ would be attained, with the slotted-core meltdown loading, as the result of a temperaturelimited transient initiated from $30^{\circ} \mathrm{C}$ with $2.95 \%(2.77 \%) \mathrm{k}_{\text {ex. }}{ }^{* *}$ Hence, the maximum allowable constant-power transient for a given $k_{e x}(0)$ could be defined in either of 2 ways:

(1) a constant-power duration giving a total integrated power, which would produce a maximum core temperature of $400^{\circ} \mathrm{C}$;

(2) a constant-power transient with a total available $\mathrm{k}_{\mathrm{ex}}$ (initial $\mathrm{k}_{\mathrm{ex}}$ and sustaining $\mathrm{k}_{\mathrm{ex}}$ ) of $2.95 \%(2.77 \%)$.

The more conservative second definition has been adopted. Its extension to values of limiting $\mathrm{k}_{\mathrm{ex}}$ below the maximum allowable of $2.95 \%(2.77 \%)$, which result from specific analysis of individual meltdown experiments, is straightforward.

The practical difference in the 2 criteria is considerable. ${ }^{\dagger}$ Figure 37 shows the calculated duration of ideal constant-power transients based on the following criteriatt:
A. maximum reactor temperature $=400^{\circ} \mathrm{C}$
B. $\mathrm{k}_{\mathrm{ex}}(0)+$ sustaining $\mathrm{k}_{\mathrm{ex}}=2.95 \%$
$\mathrm{B}^{\prime} \cdot \mathrm{k}_{\mathrm{ex}}(0)+$ sustaining $\mathrm{k}_{\mathrm{ex}}=2.77 \%$
C. $\mathrm{k}_{\mathrm{ex}}(0)+$ sustaining $\mathrm{k}_{\mathrm{ex}}=1.50 \%$
D. $\mathrm{k}_{\mathrm{ex}}(0)+$ sustaining $\mathrm{k}_{\mathrm{ex}}=1.10 \%$.

*Based on the estimate that the Zircaloy cladding of TREAT fuel would have a lifetime of "years" of continuous operation at $400^{\circ} \mathrm{C} .(5)$

**The latter value is obtained from calculations with the slotted-core feedback; the former assumes the solid-core feedback. Calculations for both have been made and the results will be noted in this manner.

†The general case may be most easily treated in the approximation of no delayed neutrons and a feedback relation $\Delta \mathrm{k}_{\mathrm{ex}}=-\mathrm{b} \int \mathrm{ndt}$. For an instantaneous addition of $\mathrm{k}_{\mathrm{ex}}(0)=\mathrm{k}_{1}+\mathrm{k}_{2}$, the total burst integrated neutron density is $2\left(k_{1}+k_{2}\right) / b$. For $k_{e x}(0)=k_{1}$, and power maintained at the peak by sustaining $k_{e x}=k_{2}$, the total burst integrated neutron density becomes $\left(2 \mathrm{k}_{1}+\mathrm{k}_{2}\right) / \mathrm{b}$.

${ }^{\dagger}$ Total $\mathrm{k}_{\mathrm{ex}}$ values of 1.50 and $1.10 \%$ are typical limitations for specific experiments that have been performed. As previously stated, a $\mathrm{k}_{\mathrm{ex}}(0)+$ sustaining $\mathrm{k}_{\mathrm{ex}}$ of $2.95 \mathrm{using}$ the solid-core feedback (or $2.77 \%$ and the slotted-core feedback) will result in a maximum core temperature of $400^{\circ} \mathrm{C}$ if the total available $k_{\mathrm{ex}}$ accidentally initiates the transient. 
For the calculation of the first case, simplifying assumption was made that the integrated power generated after the end of the constant-power portion was negligible.

It should be noted

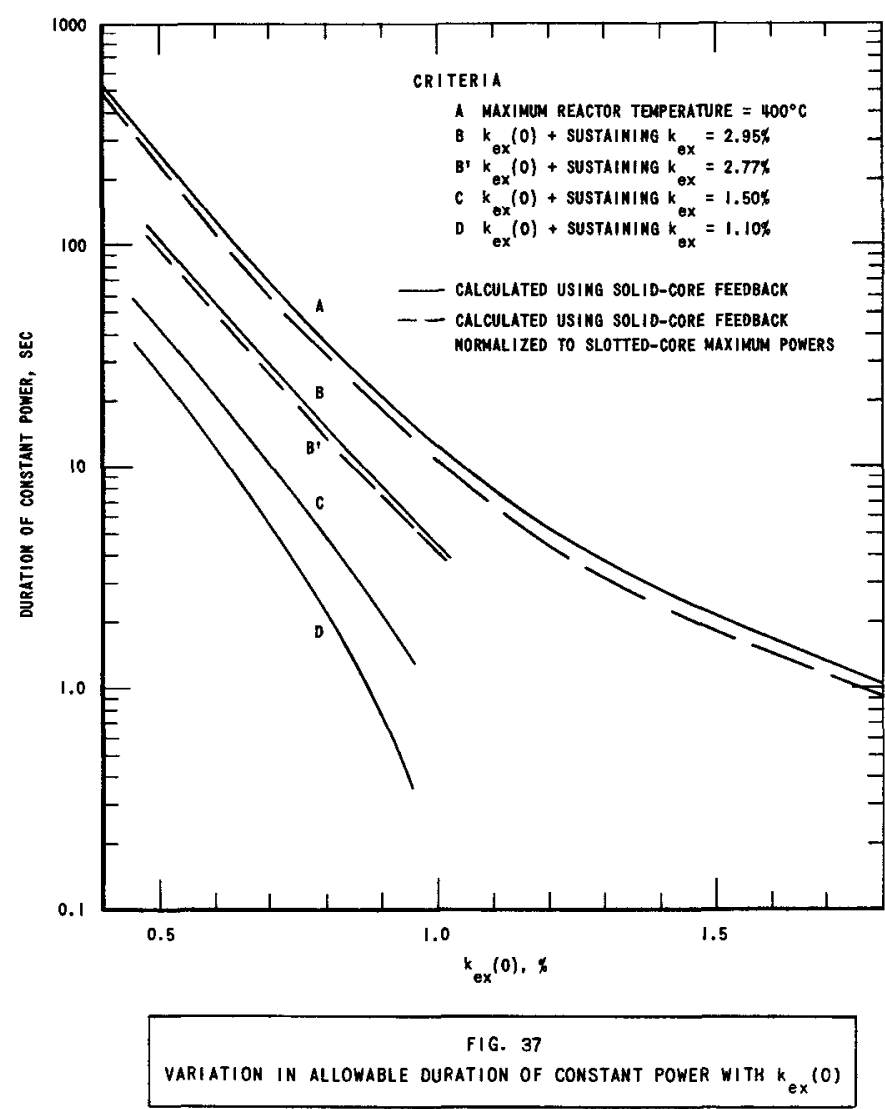

that the integrated reactor power developed up to the end of the constant-power portion for these ideal transients is not exactly equal to the integrated power to the temperaturelimited maximum plus the product of that maximum power and the duration. During the "constant power" portion of the transient, the neutron density remains constant, but the total reactor power increases slowly, because the "effective size" of the reactor increases as the sustaining rod motion removes control-rod poison from the core. For typical meltdown transients, this increase is of the order of a few percent, $4 \%$; hence, it increases the integrated power by $\sim 2 \%$. Accordingly, in this report no distinction will be made between the case of constant-neutron-density transient for which this power increase occurs, and the case of constant-reactorpower transients for which an equal and opposite change of neutron density occurs.* The effective size of the core during a constant-power burst will be assumed to be constant and equal to the effective size determined by the $\mathrm{k}_{\mathrm{ex}}(0)$.

*This magnitude of increase or decrease is well within actual power variations observed in experimental constant-power transients, and is comparable to variations in temperature-limited power peaks caused by typical deviations in $\mathrm{k}_{\mathrm{ex}}(0)$. Over the $\mathrm{k}_{\mathrm{ex}}(0)$ region of principal meltdown experimentation interest,

$$
\frac{\Delta \mathrm{P}_{\mathrm{t}}}{\Delta \mathrm{P}_{\mathrm{t}}} \sim 4 \frac{\Delta \mathrm{k}_{\mathrm{ex}}(0)}{\mathrm{k}_{\mathrm{ex}}(0)},
$$

where $P_{t}$ is the temperature-limited maximum power (see Fig. 17). Hence, if a constant-power transient planned for $\mathrm{k}_{\mathrm{ex}}(0)=0.60 \%$ were actually run with $\mathrm{k}_{\mathrm{ex}}(0)=0.61 \%$, the difference between the planned and actual temperature-limited peak power would be $\sim 7 \%$ (assuming no experimental scatter). 
Results of the calculations of maximum transient durations as a function of $\mathrm{k}_{\mathrm{ex}}(0)$ and different limitation criteria may also be presented as maximum allowable integrated power. Curves of maximum integrated power for the criteria employed for Fig. 37 are shown in Fig. 38. Here, it was assumed that no integrated power was generated after the finish of the constant-power region. The curves of Fig. 38 thus apply to ideal constantpower transients terminated by rod scram. Hence, if there were no scram, the actual integrated power of the curve for limitation A would be appreciably higher and violate the core-temperature limitation. In the cases of limitations $B, C$, and $D$, absence of rod scram would increase the total integrated powers above those shown, but the respective total $k_{\text {ex }}$ criteria would not be exceeded and the limitations would not be violated. The slight increase in total integrated power as $\mathrm{k}_{\mathrm{ex}}(0)$ increases for the limitation $\mathrm{A}$ is due to the increased effective core size with greater $\mathrm{k}_{\mathrm{ex}}(0)$. For the other limitations, the details of the feedback relationship curve and the relative effectiveness of sustaining $k_{\mathrm{ex}}$ and $\mathrm{k}_{\mathrm{ex}}(0)$ become important. Note the considerable decrease in total integrated power as $k_{e x}(0)$ increases for the limitation of total $\mathrm{k}_{\mathrm{ex}}=1.10 \%$.

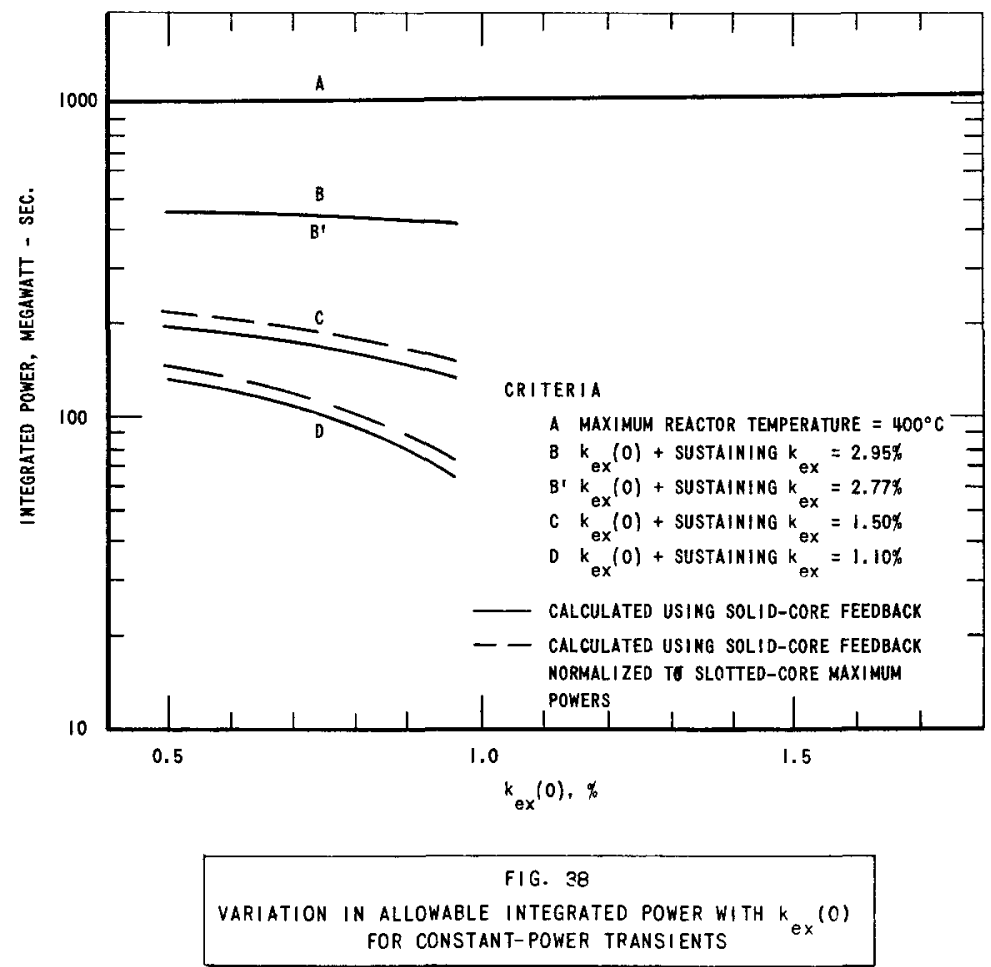

In determining the curves for Figs. 37 and 38, calculations based on both the solid-core and slotted-core feedbacks were made for each limiting criterion. First, the total integrated power for limitation $A$ was found. This curve is identical for both feedback relations, as it depends only upon the desired initial and final temperatures and the initial $\mathrm{k}_{\mathrm{ex}}$. The duration of the constant power for this criterion was calculated by means of Equation 11, in which the proper integrated power to peak was 
substituted. As the power and integrated power to peak for the clotted-core feedback are $10 \%$ greater than the values determined by the solid-core feedback, and as each $\mathrm{k}_{\mathrm{ex}}(0)$ yields only a single value of total integrated power, the slotted-core feedback gives a constant-power duration curve about $10 \%$ below that for the solid-core feedback.

Because of the increased slotted-core feedback power levels, the temperature attained by a $60-\mathrm{sec}$ temperature-limited transient of given $k_{\text {ex }}(0)$ is higher than if the solid-core feedback were used. Thus, the total $k_{\text {ex }}$ needed to reach the $400^{\circ} \mathrm{C}$ maximum temperature (limitation $B$ ) is smaller for the slotted-core feedback $(2.77 \%$ as opposed to $2.95 \%$ for the solid-core feedback). Since the sustaining $k_{e x}(t)$ curves are independent of the feedback relation used, a shorter duration of constant power is again obtained for the slotted-core feedback. However, the shorter duration is nearly balanced by the higher constant-power level for the slotted-core feedback, and essentially the same value of total integrated power results for each $\mathrm{k}_{\mathrm{ex}}(0)$.

For limitations $C$ and $D$, the constant-power durations are identical for both feedback relations since the total $\mathrm{k}_{\mathrm{ex}}$ values are equal. It follows that the corresponding integrated power curves have a $10 \%$ separation with the slotted-core feedback curve being the higher.

Figures 39 through 43 are power curves for 5 experimental constant-power transients. The figures indicate some of the difficulties in obtaining this type of excursion satisfactorily. The most important of these difficulties involves addition of the sustaining $k_{e x}$ in a manner such that the temperature-limited maximum power is maintained.

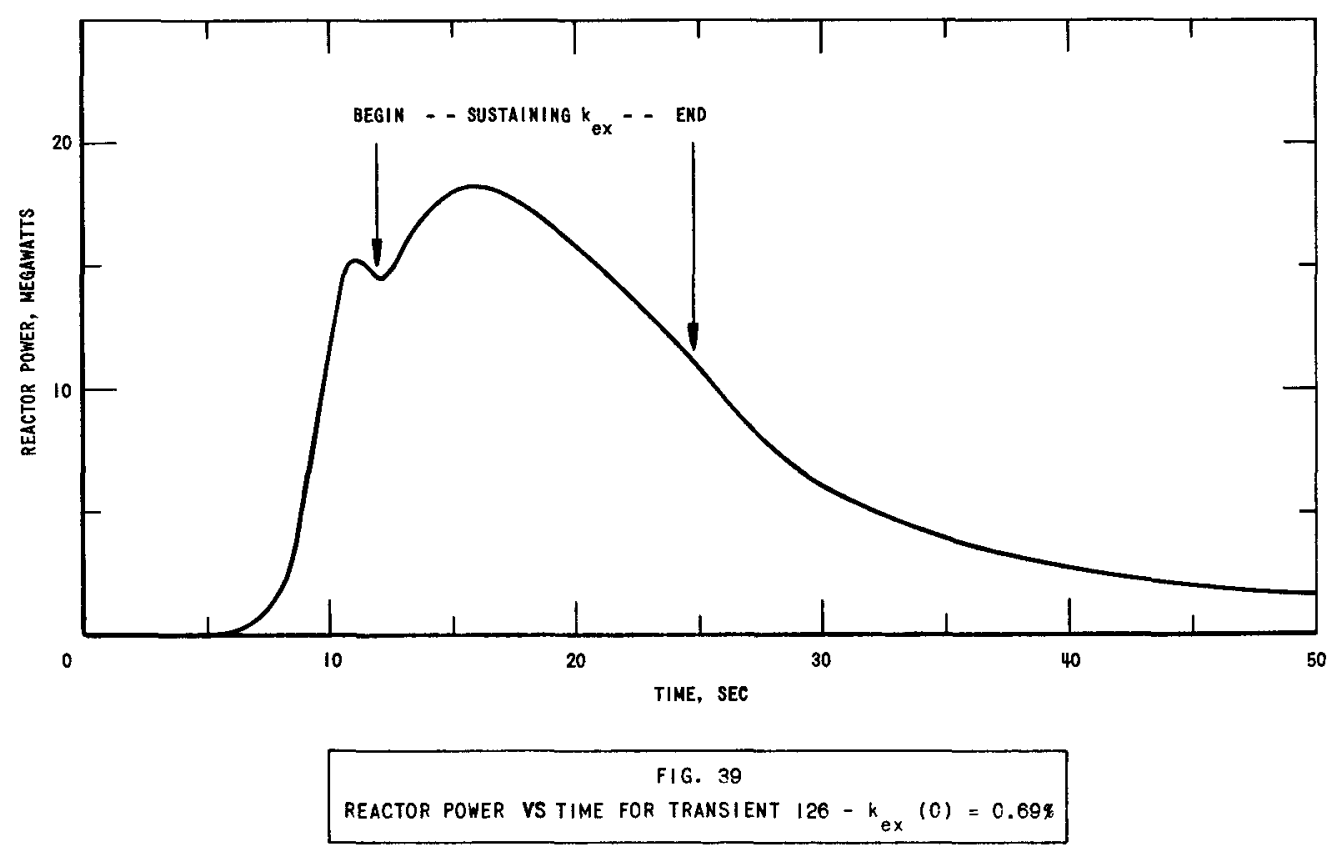


51

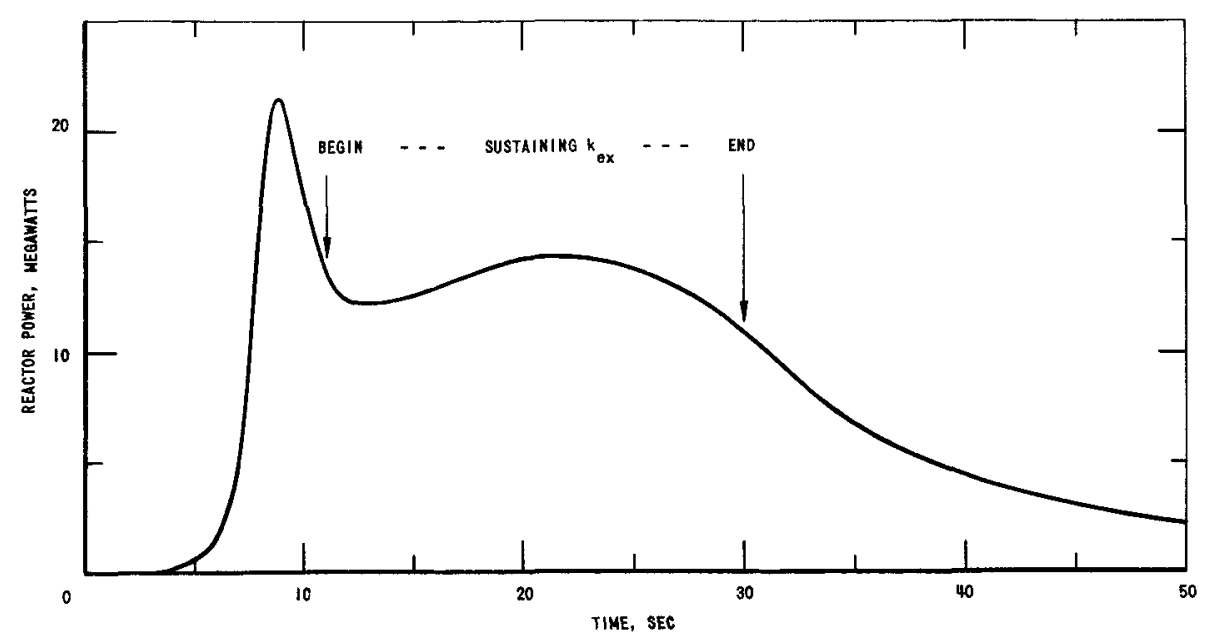

FIG. 40
REACTOR POWER VS TIME FOR TRANSIENT $127-k_{\text {ex }}(0)=0.74 \pi$

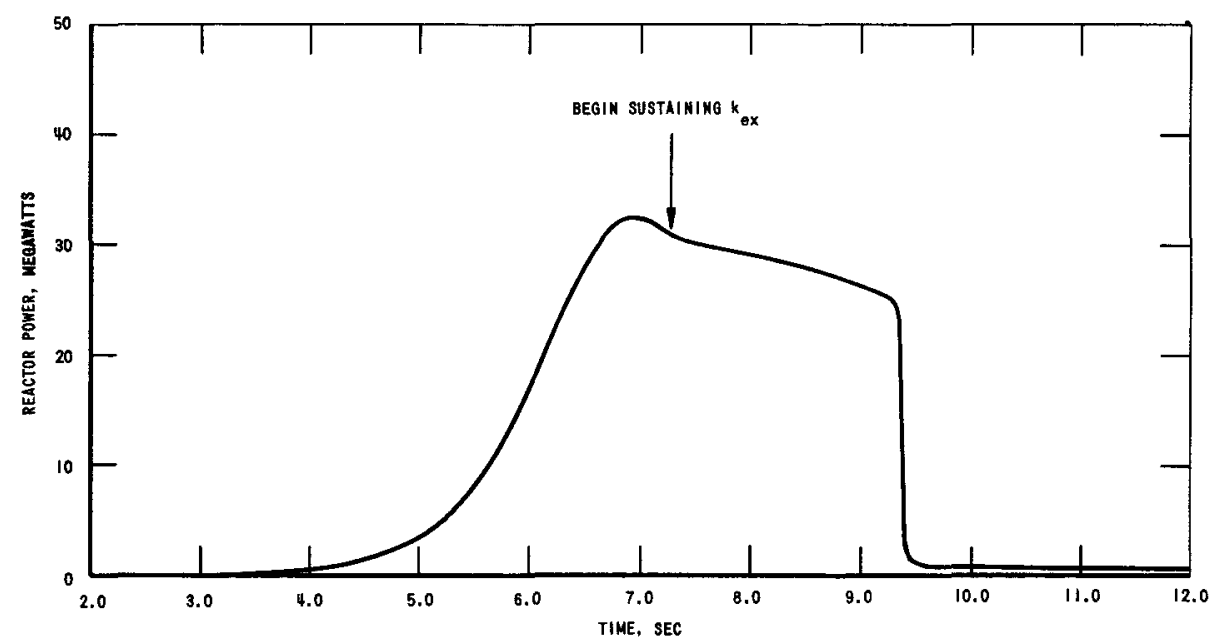

REACTOR POWER VS TIME FOR TRANSIENT $|6|-k_{\text {ex }}(0)=0.81 \%$

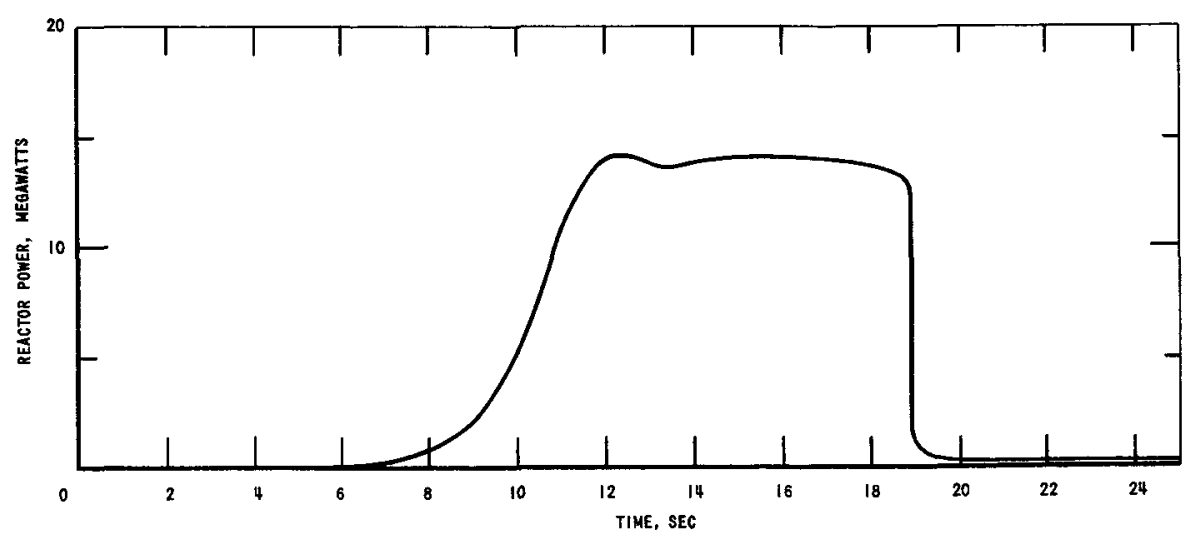

REACTOR POWER VS TIME FOR TRANSIENT $231-k_{\text {ex }}(0)=0.67 \%$ 


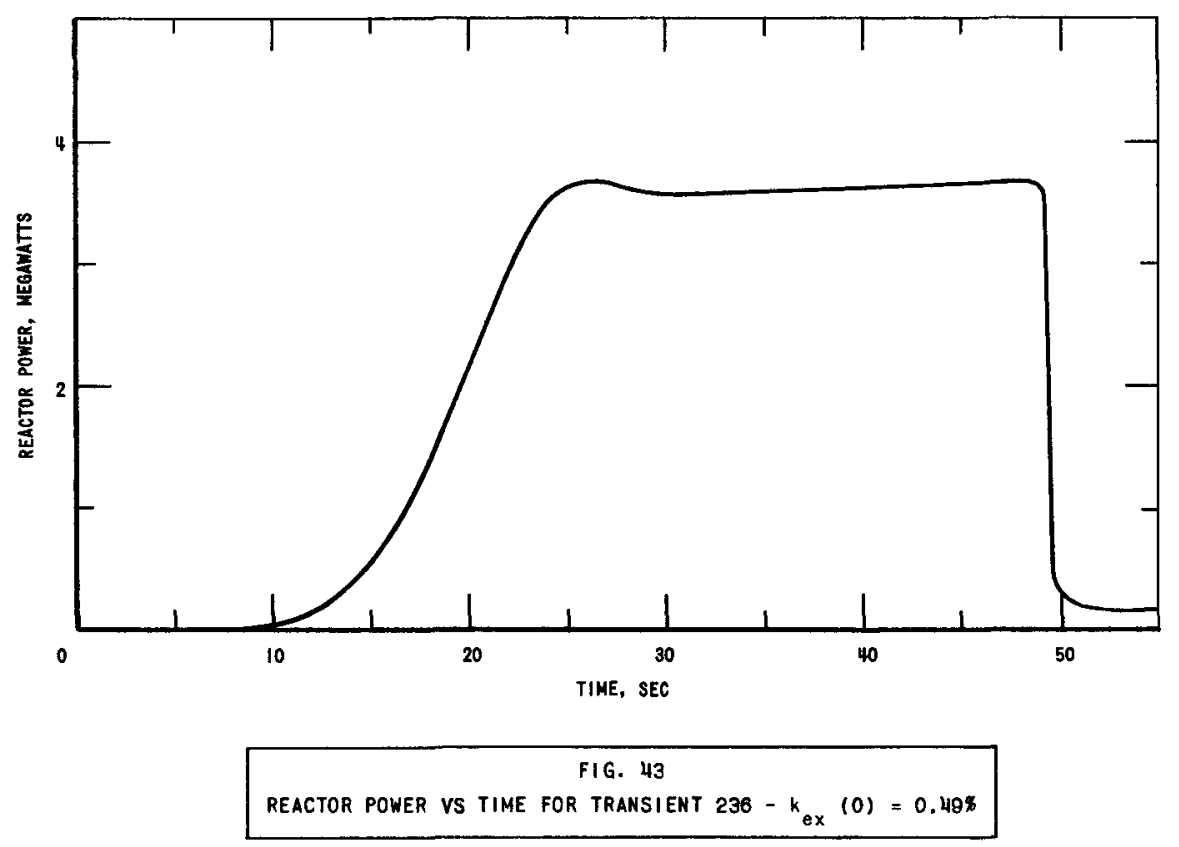

The first problem is to determine when to start the sustaining $k_{e x}$. It must begin promptly with the temperature-limited peak, and 3 methods are available for ascertaining the peak:

(1) The time of the peak may be predicted from previous transients of the same $k_{e x}(0)$ and reactor configuration.

(2) The maximum power level may be predicted from the $k_{\mathrm{ex}}(0)$ and Fig. 17.

(3) The time derivative of reactor power may be taken during the actual transient.

The first method assumes that the initial reactor conditions, including the value of $\mathrm{k}_{\mathrm{ex}}(0)$, can be accurately reproduced. Attempts have been made to perform groups of identical $k_{e x}(0)$ transients, and the results have shown an average variation in $\mathbf{k}_{\mathrm{ex}}(0)$ of $\sim 3 \%$ of the desired value. This places a limit on the accuracy of predicted peak times. Nevertheless, in several early constant-power excursions, the sustaining $\mathrm{k}_{\mathrm{ex}}$ was started at a preset time which, it was hoped, was near the peak. The transients of Figs. 39 and 40 were of this type.

The second method starts the sustaining $k_{\text {ex }}$ when the reactor has attained a preselected power level. The power level of the temperaturelimited peak is sensitively dependent upon the $\mathrm{k}_{\mathrm{ex}}(0)$, and, therefore, this method is also subject to the inability to obtain the desired $\mathrm{k}_{\mathrm{ex}}(0)$ within $\sim 3 \%$. No constant-power transients have been performed by means of this method of determining the proper time to begin the sustaining $\mathrm{k}_{\mathrm{ex}}$. 
Taking the time derivative of the reactor power during the excursion allows the peak to be determined independently of the reactor configuration, the power level actually attained, and errors in $k_{e x}(0)$. The sustaining $k_{e x}$ in this case is begun when a differentiating circuit observes a negative time derivative of reactor power. This method has been used for all recent constant-power transients, including those of Figs. 41, 42, and 43. Examination of these figures will show that the sustaining $k_{e x}$ always began slightly after the peak. This is mainly due to a delay in the rod drive mechanism between starting signal and the actual rod movement. The empirical approach has been used to obtain desired power curve shapes. Rod position, rod speed, and negative derivative trip setting have been varied.

If the sustaining $\mathrm{k}_{\mathrm{ex}}$ is begun at the proper time, the curve of the sustaining $k_{e x}$ vs time still must have the correct shape to maintain the power. Supplying the sustaining $\mathrm{k}_{\mathrm{ex}}$ too rapidly will cause the reactor power to increase; similarly, the rate of reactor power decrease will only be reduced if sustaining $k_{e x}$ is supplied too slowly.

The sustaining $\mathrm{k}_{\mathrm{ex}}$ of Fig. 39 was added at a rate initially greater than necessary to maintain the power at the time addition began. However, this rate was not sufficient to compensate for the reactor heating at the resulting higher peak power. Thus, the power rapidly increased at first, and then slowly decreased. At about $25 \mathrm{sec}$, the sustaining $\mathrm{k}_{\mathrm{ex}}$ ceased, and the power continued to decrease in the fashion of a temperaturelimited excursion. The average power during the sustaining $\mathrm{k}_{\mathrm{ex}}$ period was very nearly that of the initial temperature-limited peak.

In Fig. 40, the sustaining $\mathrm{k}_{\text {ex }}$ was begun well after the peak, and the power level maintained was below the temperature-limited maximum. Again, too much sustaining $k_{e x}$ was added, which caused the power first to increase and then to fall off as the reactor heated. At about $30 \mathrm{sec}$, the sustaining $k_{e x}$ ended and the transient was allowed to continue in $a$ temperature-limited manner.

The sustaining rate of addition of $k_{\mathrm{ex}}$ of Fig. 41 was insufficient to balance the removal of $\mathrm{k}_{\mathrm{ex}}$ by reactor heating, and the power level decreased constantly until the reactor was scrammed at about $9.3 \mathrm{sec}$.

The sustaining $\mathrm{k}_{\mathrm{ex}}$ of Transient 231 (Fig. 42) was begun somewhat after the peak, and was added at a rate only slightly greater than the calculated ideal. The power increased to $14.1 \mathrm{Mw}$ and then had fallen to about $13.2 \mathrm{Mw}$ when scram occurred at $18.7 \mathrm{sec}$. The average power during this time was $13.8 \mathrm{Mw}$ with a variation of $\sim 4 \%$. 
Figure 43 is the power curve from the best constant-power transient obtained to date. The sustaining $k_{e x}$ began slightly after the peak and was added at very nearly the ideal rate, as the power varied only from 3.56 to $3.67 \mathrm{Mw}$ over a period of some $20 \mathrm{sec}$. The average "constant" power for this transient was $3.61 \mathrm{Mw}$, with a variation of $1.5 \%$. 


\section{PERFORMANCE EXTRAPOLATIONS}

Extrapolations of temperature-limited transient performance for maximum core temperatures in the range from 400 to $700^{\circ} \mathrm{C}$ in the TREAT reactor have been presented for the simple, solid-core loading. (7) Because of changes in feedback, core temperature distribution, and effective core size produced by the large perturbations in the core for typical slotted, meltdown experimental loadings, those extrapolations do not apply to loadings similar to that considered herein. The theoretical solid-core feedback and this feedback normalized to the slotted-core maximum reactor powers, together with estimates of effective reactor size, have been utilized to extrapolate performance beyond that studied experimentally. Starting temperature was $30^{\circ} \mathrm{C}$.

Based on the comparisons of Section III, the following general predictions may be made about the extrapolations:

(1) Extrapolations of maximum transient power by means of the slotted-core feedback should be close to measured values.

(2) Extrapolations of integrated transient power based on both feedbacks should bracket the experimental values, the solid-core feedback giving the better results.

(3) Extrapolations of maximum core temperature should also bracket the measured results with somewhat less error than found in the extrapolation of integrated transient power, because of the nonconstant specific heat of the fuel which increases with increasing temperature, and the use of an empirical maximum-to-average neutron-density factor.

Extrapolations of maximum transient power are shown in Fig. 44. The extrapolations of integrated transient power at $60 \mathrm{sec}$ are displayed in Fig. 45, and the extrapolations of maximum core temperature by means of a reactor maximum-to-average neutron-density ratio of 1.7 are given in Fig. 46. The energy correction of $9 \mathrm{Mev}$ per fission decay was used in both Fig. 45 and Fig. 46.

The figures indicate that, if the solid-core feedback is used, the maximum core temperature of $400^{\circ} \mathrm{C}$ would be reached during a temperaturelimited transient of $2.95 \% \mathrm{k}_{\mathrm{ex}}(0) .^{*}$ This transient would yield an integrated power at $60 \mathrm{sec}$ of $1150 \mathrm{Mw}-\mathrm{sec}$. The corresponding values for the slottedcore feedback are $2.77 \%$ and $1140 \mathrm{Mw}-\mathrm{sec}$. Although the same integrated neutron density is attained in both transients, the inequality of integrated powers is due to the difference in initial $k_{e x}$, which gives slightly different values of $\mathrm{N}_{e}$, the effective core size.

* The most severe transient run with TREAT was initiated with $2.95 \% \mathrm{kex}$ and attained a maximum power of $4400 \mathrm{Mw}$ and an integrated power of $1010 \mathrm{Mw}-\mathrm{sec}$. 


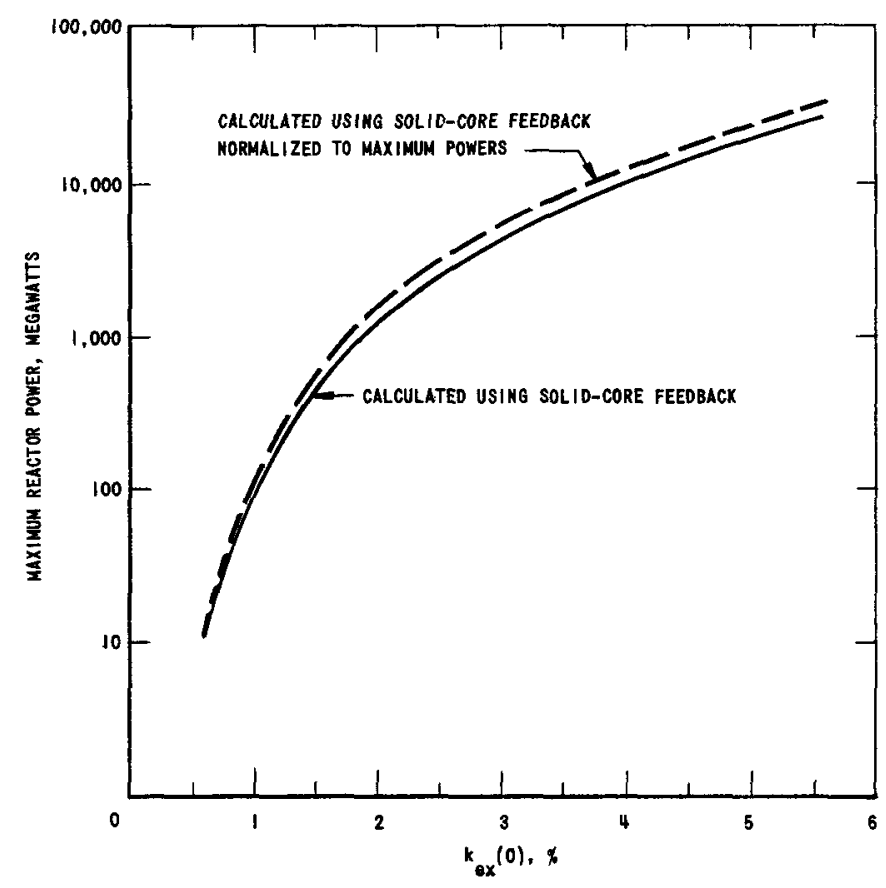

FIG. 44

EXTRAPOLATION OF MAXIMUM TRANSIENT POWER FOR TEMPERATURE - LIMITED TRANSIENTS, SLOTTED CORE LOADING

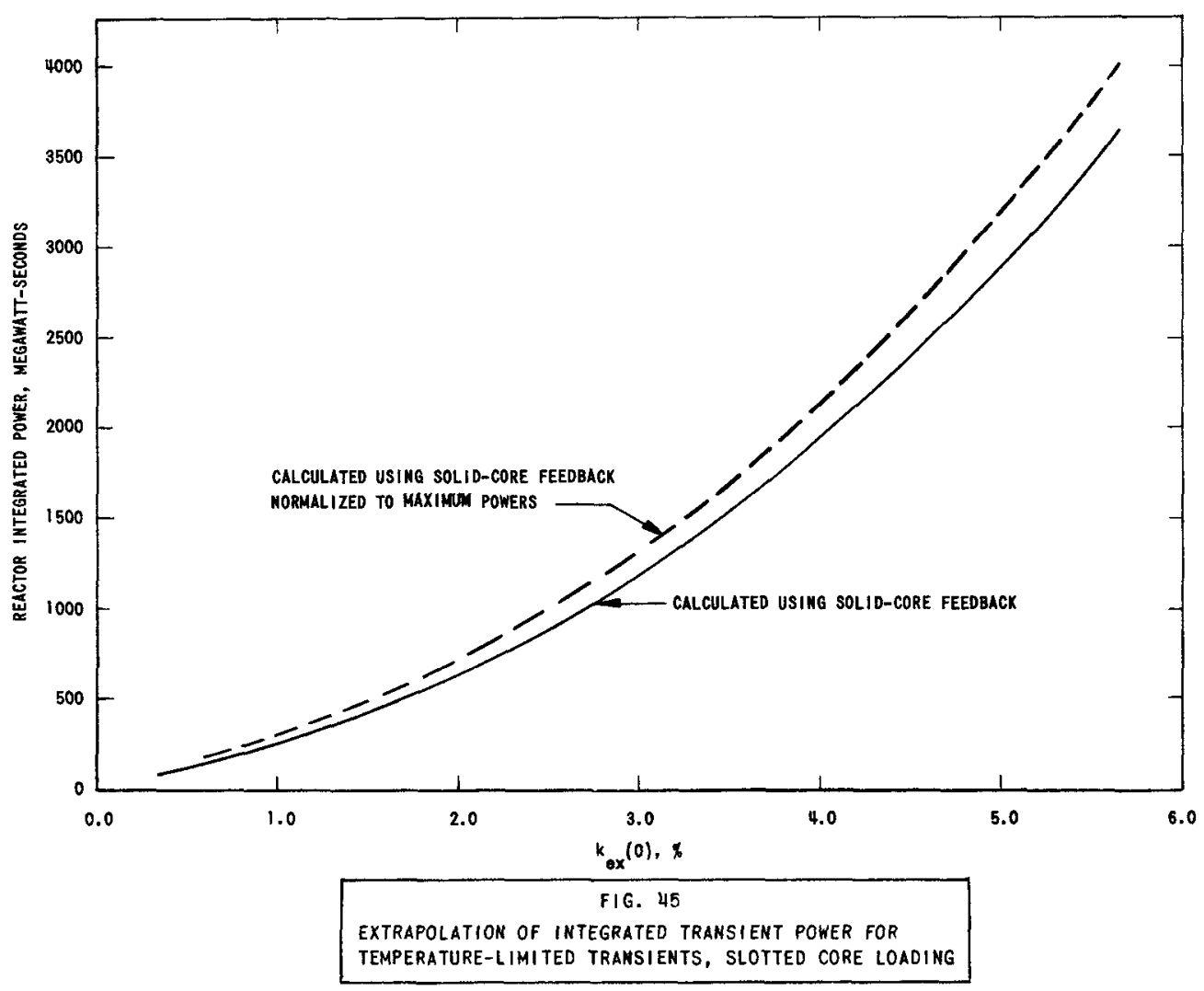




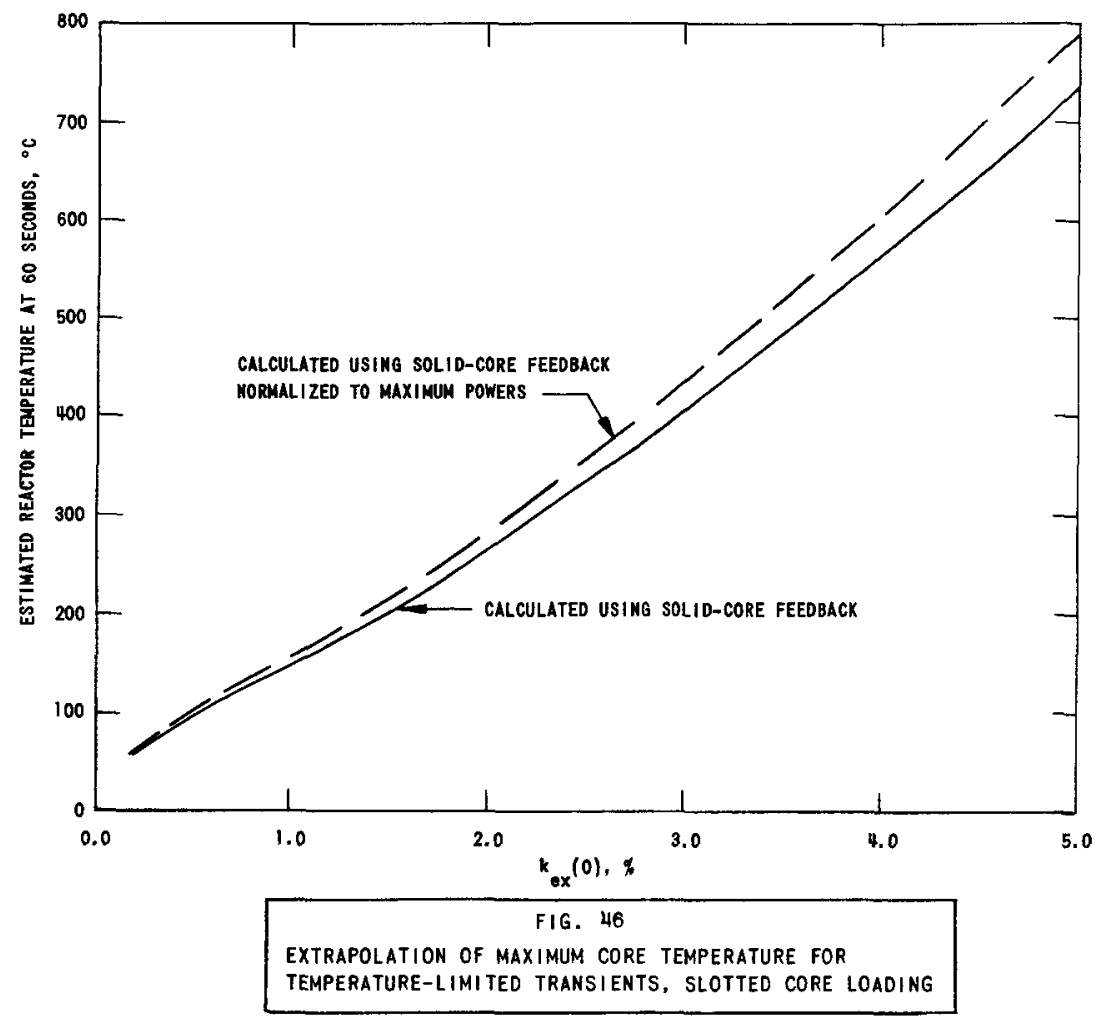

The maximum core temperature of $700^{\circ} \mathrm{C} *$ is predicted to result from a transient with a $\mathrm{k}_{\mathrm{ex}}(0)$ of $4.80 \%$ and integrated power of $2690 \mathrm{Mw}-\mathrm{sec}$ if the solid-core feedback is used. The slotted-core feedback indicates values of $4.52 \%$ and $2670 \mathrm{Mw}-\mathrm{sec}$.

Comparison of the se extrapolations and new ones for the solid core is given in Table I. A slight decrease in maximum-to-average flux ratio is the cause of the increase in $k_{e x}(0)$ from the solid-core extrapolations to those of the slotted core if the solid-core feedback is used. The difference in maximum and integrated powers is due to changes in both flux ratio and effective core size. The solid-core extrapolations have been recalculated and differ somewhat from those previously reported, (7) as slightly different data and techniques have been used.

Table I

\section{COMPARISON OF SOLID-CORE AND SLOTTED-CORE EXTRAPOLATIONS}

Solid Core

$k_{\text {ex }}(0)$ for $400^{\circ} \mathrm{C}$ Max Core Temperature, $\%$ Integrated Power for $400^{\circ} \mathrm{C}, \mathrm{Mw}-\mathrm{sec}$ Maximum Power for $400^{\circ} \mathrm{C}, \mathrm{Mw}$ $\mathrm{k}_{\mathrm{ex}}(0)$ for $700^{\circ} \mathrm{C}$ Max Core Temperature, \% Integrated Power for $700^{\circ} \mathrm{C}, \mathrm{Mw}-\mathrm{sec}$ Maximum Power for $700^{\circ} \mathrm{C}, \mathrm{Mw}$

2.94
900
3,420
4.78
2,120
15,200

Slotted Core

\begin{tabular}{cc}
\hline Solid-core Feedback & Slotted-core Feedback \\
2.95 & 2.77 \\
1,150 & 1,140 \\
4,380 & 4,080 \\
4.80 & 4.52 \\
2,690 & 2,670 \\
19,300 & 18,000
\end{tabular}

* This temperature is probably the maximum for short-time operation (see Ref. 5). 


\section{ACKNOW LEDGMENTS}

The effective and efficient operation of TREAT by the operations personnel is appreciated. J. F. Boland is reactor manager, and the staff consists of H. Lawroski, F. Kirn, and R. DeForest. 


\section{REFERENCES}

1. C. E. Dickerman, E. Sowa, D. Okrent, J. Monaweck, and L. B. Miller, Studies of Fast Reactor Fuel Element Behavior under Transient Heating to Failure I. Initial Experiments on Metallic Samples in the Absence of Coolant, ANL-6334 (1961).

2. G. A. Freund, H.P. Iskenderian, and D. Okrent, TREAT, A Pulsed Graphite-moderated Reactor for Kinetic Experiments, Proceedings of the Second United Nations International Conference on the Peaceful Uses of Atomic Energy, Geneva, Switzerland, 10, 461 (1958).

3. H. P. Iskenderian, Physics Analyses of the TREAT Reactor Design, ANL-6025 (1959).

4. H. P. Iskenderian, Post Criticality Studies on the TREAT Reactor, ANL-6115 (1960).

5. D. R. MacFarlane, G. A. Freund, and J.F. Boland, Hazards Summary Report on TREAT, ANL-5923 (1958).

6. G. A. Freund, P. Elias, D. R. MacFarlane, J. D. Geier, and J. F. Boland, Design Summary Report on the Transient Reactor Test Facility TREAT, ANL-6034 (1960).

7. D. Okrent, C. E. Dickerman, J. Gasidlo, D. M. O'Shea, and D. F. Schoeberle, The Reactor Kinetics of the Transient Reactor Test Facility (TREAT), ANL-6174(1960).

8. F. Kirn, J.F. Boland, R. D. Cook, and H. Lawroski, Reactor Physics Measurements in TREAT, ANL-6173 (1960).

9. R. C. Liimatainen, R. O. Ivins, M. F. Deerwester, and F. J. Testa, Studies of Metal-Water Reactions at High Temperatures II. TREAT Experiments: Status Report on Results with Aluminum, Stainless Steel 304, Uranium, and Zircaloy II, ANL-6250 (To be published).

10. C. E. Cohn and B. J. Toppel, unpublished.

11. I. G. Baksys, unpublished.

12. M. Butler, unpublished.

13. R. O. Brittan, Some Problems on the Safety of Fast Reactors, ANI-5577 (1956). 
14. D. F. Schoeberle, unpublished.

15. R. V. Batch, Design and Development Report on TREAT Control Rod Drive II, ANI-6350(1961).

16. J. F. Boland, Idaho Division Summary Report October 1960 through 1961, ANL-6392(1961), p. 38 . 